\title{
Parameterising secondary organic aerosol from $\alpha$-pinene using a detailed oxidation and aerosol formation model
}

\author{
K. Ceulemans, S. Compernolle, and J.-F. Müller \\ Belgian Institute for Space Aeronomy (BIRA-IASB), Brussels, Belgium \\ Correspondence to: K. Ceulemans (karl.ceulemans@aeronomie.be) \\ Received: 14 March 2011 - Published in Atmos. Chem. Phys. Discuss.: 18 August 2011 \\ Revised: 1 June 2012 - Accepted: 4 June 2012 - Published: 19 June 2012
}

\begin{abstract}
A new parameter model for $\alpha$-pinene secondary organic aerosol (SOA) is presented, based on simulations with the detailed model BOREAM (Biogenic hydrocarbon Oxidation and Related Aerosol formation Model). The parameterisation takes into account the influence of temperature, type of oxidant, $\mathrm{NO}_{\mathrm{x}}$-regime, photochemical ageing and water uptake, and is suitable for use in global chemistry transport models. BOREAM is validated against recent photooxidation smog chamber experiments, for which it reproduces SOA yields to within a factor of 2 in most cases. In the simple chemical mechanism of the parameter model, oxidation of $\alpha$-pinene generates peroxy radicals, which, upon reaction with $\mathrm{NO}$ or $\mathrm{HO}_{2}$, yield products corresponding to high or low- $\mathrm{NO}_{\mathrm{x}}$ conditions, respectively. The model parameters - i.e. the temperature-dependent stoichiometric coefficients and partitioning coefficients of 10 semi-volatile products - are obtained from simulations with BOREAM, including a prescribed diurnal cycle for the radiation, oxidant and emission levels, as well as a deposition sink for the particulate and gaseous products. The effects of photooxidative ageing are implicitly included in the parameterisation, since it is based on near-equilibrium SOA concentrations, obtained through simulations of a two-week period. In order to mimic the full BOREAM model results both during SOA build-up and when SOA has reached an equilibrium concentration, the revolatilisation of condensable products due to photochemical processes is taken into account through a fitted pseudo-photolysis reaction of the lumped semi-volatile products. Modelled SOA mass yields are about ten times higher in low- $\mathrm{NO}_{\mathrm{x}}$ than in high- $\mathrm{NO}_{\mathrm{x}}$ conditions, with yields of more than $50 \%$ in the low- $\mathrm{NO}_{\mathrm{x}} \mathrm{OH}$-initiated oxidation of $\alpha$-pinene, considerably more than in previous parameterisations based on smog chamber experiments. Sensitivity cal-
\end{abstract}

culations indicate that discrepancies between the full model and the parameterisation due to variations in assumed oxidant levels are limited, but that changes in the radiation levels can lead to larger deviations. Photolysis of species in the particulate phase is found to strongly reduce SOA yields in the full model. Simulations of ambient conditions at 17 different sites (using oxidant, radiation and meteorological data from a global chemistry-transport model) show that overall, the parameterisation displays only little bias $(2 \%)$ compared with the full model, whereas averaged relative deviations amount to about $11 \%$. Water uptake is parameterised using fitted activity coefficients, resulting in a good agreement with the full model.

\section{Introduction}

Aerosols play an important role in the Earth's atmosphere through their impact on climate (Solomon et al., 2007) and air quality (Pope III et al., 2002; Krewski et al., 2009). Organic material often makes up more than $50 \%$ of atmospheric aerosols, of which an important fraction is secondary organic aerosol (SOA), containing semi-volatile gas phase oxidation products of volatile organic compounds (VOC), that partition between the gas and aerosol phase (Jimenez et al., 2009). Several VOC have been identified as important SOA precursors through smog chamber experiments, such as aromatic compounds, mostly of anthropogenic origin $(\mathrm{Ng}$ et al., 2007b), and biogenic species such as the monoterpenes (for examples, see references in Sect. 2.5), sesquiterpenes (Ng et al., 2007a), isoprene (Kroll et al., 2006) and dicarbonyls (Volkamer et al., 2009). The monoterpene $\alpha$ pinene is one of the volatile organic compounds whose SOA 
formation mechanism has received most attention. Numerous smog chamber studies have been conducted, aimed at monitoring SOA yields and elucidating the gas phase and aerosol phase composition and chemical mechanisms, which were either "dark ozonolysis" (see for example the experiments cited in Table 1 in Ceulemans et al., 2010) or "photooxidation" experiments (see Sect. 2.5).

Experimental results have been combined with structureactivity relationships, and sometimes theoretical quantumlevel calculations (Peeters et al., 2001), to construct detailed mechanisms for the gas phase oxidation of $\alpha$-pinene, which have been supplemented with a partitioning model (Kamens and Jaoui, 2001; Jenkin, 2004; Capouet et al., 2008; Xia et al., 2008; Valorso et al., 2011). Such detailed mechanisms are often too large for use in global chemistry transport models, however. Moreover, these models still contain many uncertainties (Hallquist et al., 2009), which can lead to discrepancies between modelled and experimental SOA yields (Xia et al., 2008; Ceulemans et al., 2010; Valorso et al., 2011). Another approach towards SOA modelling has been the direct fitting of parameterised two-product models for SOA formation to experimental SOA mass yields (Odum et al., 1996), and for $\alpha$-pinene a number of parameterisations has been derived (see Sect. 3.5). Most smog chamber experiments were hitherto conducted under conditions which, for one or more aspects, differ from those which can be found in the atmosphere: initial VOC loadings are often higher, $\mathrm{NO}_{\mathrm{x}}$ concentrations might differ, $\mathrm{OH}$-scavengers might be used, and their run-time is often relatively short - several hours while atmospheric photochemical ageing might continue for several days. Parameterisations based on experimental studies lack some of the sensitivity to important factors, such as $\mathrm{NO}_{\mathrm{x}}$-regime or ageing, due to lack of reliable experimentally determined yields at various experimental configurations, or because such effects were simply ignored in the parameterisation.

A number of global modelling studies on SOA formation have made use of SOA parameterisations for various precursors (see for example Henze et al., 2008; Tsigaridis and Kanakidou, 2007; Farina et al., 2010; Pye and Seinfeld, 2010; Pye et al., 2010; Carlton et al., 2010). Biogenic precursors, and in particular the monoterpenes, are found to be major contributors to SOA, but a consensus on the contributions of the various types of organic aerosol, and on its total global production, has not been reached yet, with large differences between different models, and with measurements, remaining. In such studies, parameterisations for $\alpha$-pinene SOA are often used as a proxy for SOA from some or all of the monoterpenes.

Various factors can impact SOA yields. Increasing temperature is expected to have a decreasing effect, by increasing the saturated vapour pressure of semi-volatile compounds. SOA parameterisations (Odum et al., 1996; Presto et al., 2005a) based on SOA experiments around the same temperature do not contain an explicit temperature dependence.
In Pathak et al. (2007) dark $\alpha$-pinene experiments at temperatures between 15 and $40^{\circ} \mathrm{C}$ were conducted, and a decrease in SOA yields was observed with increasing temperature, which was smaller than the decrease predicted by the full BOREAM model (Ceulemans et al., 2010), however. Saathoff et al. (2009) conducted a large number of dark ozonolysis experiments at different temperatures, and explicitly included the temperature dependence in their parameterisation. Several global modelling studies have made use of an estimated enthalpy of vapourisation $\left(\Delta H_{\mathrm{vap}}\right)$, to account for the temperature dependence of SOA yields (Chung and Seinfeld, 2002; Henze et al., 2008; Farina et al., 2010; Pye and Seinfeld, 2010). The estimated $\Delta H_{\text {vap }}$ is still quite uncertain, but its impact on global SOA production is large, especially outside the boundary layer (Henze and Seinfeld, 2006; Farina et al., 2010). The temperature sensitivity in the parameterisation of Stanier et al. (2008) is based on an enthalpy of vapourisation derived from chamber experiments at different temperatures.

Photochemical ageing can have a strong impact on SOA composition and yields. Long-term oxidation of semivolatile compounds by $\mathrm{OH}$ was shown to be crucial (Jimenez et al., 2009). However, most previous parameterisations were based on chamber studies using OH-scavengers, and/or on experiments which did not last more than a few hours. Some recent studies have tried to remedy the absence of ageing impact on parameterised SOA yields through the use of a volatility basis set, which allows oxidation products to evolve through reactions with OH (Lane et al., 2008; Jimenez et al., 2009; Farina et al., 2010). These ageing parameterisations are still quite uncertain: they may require a number of arbitrary choices (for example the change in volatility upon reaction), as these models are still not fully constrained by adequate experimental results under atmospheric conditions. In the most recent global modelling studies (e.g. Farina et al., 2010; Pye et al., 2010) the impact of long-term ageing was ignored for biogenic VOCs.

Whereas Tsigaridis et al. (2006) only considered ozonolysis as a significant SOA source, photooxidation experiments, such as $\mathrm{Ng}$ et al. (2007a) indicated that high SOA yields are also found in the $\mathrm{OH}$-initiated oxidation of $\alpha$-pinene, especially under low- $\mathrm{NO}_{\mathrm{x}}$ conditions. Most global modelling studies use identical SOA yields for ozonolysis and $\mathrm{OH}-$ oxidation (Chung and Seinfeld, 2002; Farina et al., 2010; Pye et al., 2010). Experimentally it is difficult to fully separate the SOA yields due to these oxidants. In dark ozonolysis experiments, an $\mathrm{OH}$ scavenger limits the oxidation of $\alpha$ pinene to ozonolysis, but this also limits ageing through $\mathrm{OH}-$ oxidation. In photooxidation experiments, significant ozone levels might be present, which oxidise part of the VOC.

SOA yields from $\alpha$-pinene have been shown to decrease with increasing $\mathrm{NO}_{\mathrm{x}}$ concentrations (Presto et al., 2005a; $\mathrm{Ng}$ et al., 2007a; Capouet et al., 2008), although the same is not necessarily true for other VOCs, such as sesquiterpenes ( $\mathrm{Ng}$ et al., 2007a) and isoprene (Hoyle et al., 2011). 
Presto et al. (2005a) and Pathak et al. (2007) provided separate high and low- $\mathrm{NO}_{\mathrm{x}} \mathrm{SOA}$ yield parameterisations. Until recently, $\mathrm{NO}_{\mathrm{x}}$ dependence was not considered for biogenic species in most global models. Farina et al. (2010) and Pye et al. (2010) have employed a parameterisation with a $\mathrm{NO}_{\mathrm{x}}$ dependence for the monoterpenes, however, which follows the approach of Henze et al. (2008) for aromatics. Simulations indicate that water uptake by SOA can significantly increase SOA yields at high relative humidities (Xia, 2006; Compernolle et al., 2009). Measured growth factors show that water can be taken up in significant amounts by SOA (Meyer et al., 2009), although Engelhart et al. (2011) found only slight increases of total aerosol volume due to SOA water uptake from measurements at Crete. Water uptake by SOA has been ignored in most global modelling studies, however, due to lack of reliable and easily implementable parameterisations.

In this paper, we present a parameter model for $\alpha$-pinene SOA containing 10 condensable products, taking into account the impact of temperature, type of oxidant, $\mathrm{NO}_{\mathrm{x}}-$ regime and photochemical ageing on SOA yields. The effect of water uptake is also treated. Due to its small size, this parameterisation is easily implementable in global chemistry transport models. The parameterisation is based on simulations with the detailed model BOREAM (Capouet et al., 2008; Ceulemans et al., 2010). The use of a box model makes it possible to easily cover a wide range of photochemical conditions. The parameterisation is designed to reproduce the SOA yields at equilibrium, when the production of condensable products is balanced by losses due to deposition and photochemical degradation, after typically two weeks. A similar approach was adopted recently in Xia et al. (2011), in which a reduced mechanism consisting in a volatility basis set with further ageing reactions was designed, based on simulations with the detailed MCM mechanism for $\alpha$-pinene. Another reduced-size model designed to reproduce SOA production of a larger model (in this case the MCM v3.1) is the Common Representative Intermediates mechanism for both anthropogenic and biogenic VOC oxidation and SOA formation (Utembe et al., 2009).

Section 2 presents the BOREAM model, in particular its generic chemistry mechanism (Sect. 2.2), which represents the further-generation chemistry. The model is validated against a number of photooxidation smog-chamber studies in Sect. 2.5. Next, in Sect. 3.1 the parameter model is presented, and the adjustment of its parameters is described in Sect. 3.2. In Sect. 3.4 the sensitivity of the parameterised SOA to $\mathrm{NO}_{\mathrm{x}}, \mathrm{HO}_{\mathrm{x}}$ and radiation levels is investigated, and the parameterisation is evaluated against the full model in simulations of ambient conditions at 17 different locations around the globe, using oxidant, radiation and meteorological fields from a global chemistry-transport model. Section 3.5 presents a comparison with previous parameterisations. Finally, in Sect. 3.6, the treatment of water uptake is discussed.

\section{Full box model description}

\subsection{Gas phase chemistry mechanism}

The gas phase mechanism of the BOREAM model is described in Capouet et al. (2008). The chemistry of the radical reactions, up to primary products is based on advanced quantum chemical calculations for key reactions (Peeters et al., 2001; Vereecken et al., 2007; Capouet et al., 2008; Ceulemans et al., 2010), and on structure activity relationships (SARs) for other primary gas phase reactions. The cross reactions of peroxy radicals are represented through reactions with counter species representing different peroxy radical classes. Further chemistry of the primary products includes photolysis and reaction with $\mathrm{OH}$, ozone or $\mathrm{NO}_{3}$, which are based as much as possible on recent structure activity relationships (Capouet et al., 2008). The further generation products are lumped into so-called semi-generic and generic species classes (Capouet et al., 2008; Ceulemans et al., 2010). The semi-generic species are classes defined by their carbon number and by their functional groups, whereas their precise structure is not specified. Only the most common secondary products are described through the semigeneric scheme, as a complete description would require a prohibitively large number of categories.

\subsection{Generic chemistry}

The generic chemistry system was introduced in Capouet et al. (2008), and further extended in Ceulemans et al. (2010). Generic species are used to represent classes of lumped multi-functional compounds. In the current version of the model, generic species are defined by their carbon number (from 10 down to 6) and by one explicit functional group. Other functional groups which might be present in the multi-functional compounds which the generic species represent, are not explicitly rendered. These "implicit" functional groups still have an impact on the volatility and reactivity of the compound. Therefore the generic species are further subdivided into 11 volatility classes. Each class represents lumped organic compounds, which have a "parent compound" (the molecule resulting from replacement of the explicit functional group by one or more hydrogen atoms) with a saturated liquid vapour pressure $p_{\mathrm{L}, \text { parent }}^{0}$ falling within the volatility class range. For the highest volatility class, indicated by the letter "a", $p_{\mathrm{L}, \text { parent }}^{0}>10^{-1}$ Torr at $298 \mathrm{~K}$. Class "b" contains species with $10^{-1}$ Torr $>$ $p_{\mathrm{L}, \text { parent }}^{0}>10^{-1.5}$ Torr, etc., and for the lowest volatility class "k", $p_{\mathrm{L} \text {,parent }}^{0}<10^{-5.5}$ Torr.

In the model, the non-radical generic species themselves are then assigned a vapour pressure, determined by the contribution of its explicit group (based on Capouet and Müller, 2006), and the representative volatility class vapour pressure $p_{\mathrm{L}, \mathrm{LX}}^{0}$, taken to be equal to the geometric mean of the volatility class range for classes "b"-"j”, $10^{-0.75}$ Torr for class 
Table 1. Illustration of generic alkoxy radical reactions included in BOREAM. R2R and RO3 denote peroxy radical counters (Capouet et al., 2004). The rates of these reactions are detailed in the Supplement.

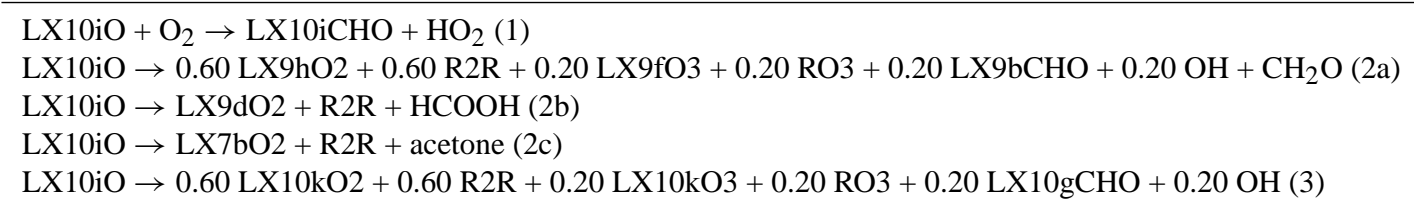

"a", and $10^{-5.75}$ Torr for class " $\mathrm{k}$ ". In our notation a generic species name consists of the prefix "LX", the carbon number, the vapour pressure class symbol and the explicit functional group. In total there are 55 classes $(5$ carbon numbers times eleven vapour pressure classes), besides the generic products with less than 6 carbon atoms, which are not considered for SOA formation, and lumped into a special generic class (with prefix “SX"). Each class includes 13 gas phase species: 3 radical species (alkoxy, peroxy and acyl peroxy) and 10 molecular species, and their chemistry is described by 86 reactions for each class (see Sect. S1 in the Supplement).

Molecular generic compounds can react with the $\mathrm{OH}$ radical or undergo photolysis. The rates of reactions involving the explicitly represented functional group are obtained through structure activity relationships, as for the explicit molecular products. In order to account for the reactivity of the implicit part of the generic compounds, we assume that generic species with lower vapour pressures are more functionalised, and therefore generally more reactive. On the basis of simple assumptions, described in the Supplement, the OH-reactivity and photolysis rates have been assigned. Whereas reactions such as photolysis or alkoxy-radical decomposition lead to a loss of carbon atoms or functional groups from the molecule, other reactions might add functional groups to the implicit part of the molecule. In each case, the product of the reaction is assigned to the appropriate carbon number/volatility class.

The generic alkoxy radicals can undergo three types of reactions (Table 1): reaction with $\mathrm{O}_{2}$, leading to a carbonyl function (1), decomposition (2) or H-shift isomerisation (3). The reaction with $\mathrm{O}_{2}$ usually has a reaction rate of the order $3-8 \times 10^{4} \mathrm{~s}^{-1}$, and is not strongly dependent on the structure of the alkoxy radical, in contrast with the reaction rates for decomposition or H-shift isomerisation (see Vereecken and Peeters, 2009, 2010). Three types of decomposition are considered: decomposition into an alkyl radical and $\mathrm{CH}_{2} \mathrm{O}$, when the alkoxy radical is primary; formic acid elimination, when the alkoxy radical contains an alcohol group; and acetone elimination. Other types of decomposition, for example breaking of a ring structure, are not considered. The branching ratio estimates are based on the reactions of the explicit alkoxy radicals present in BOREAM (see Capouet et al., 2004, 2008). It is found that decomposition occurs in most cases, followed by H-shift isomerisation. Decomposition of alkoxy radicals is favoured by the presence of oxygenated functional groups (Vereecken and Peeters, 2009). It is therefore assumed that lower volatility compounds, which generally have more functional groups, have a higher branching towards decomposition. Among the decompositions, type (Reaction 2a) (Table 1) is most common. The implicit part of the generic species changes upon decomposition or H-shift isomerisation. In particular, the product generally belongs to a different volatility class than the reactant. This is illustrated with two examples from Table 1.

In Reaction (2c), the reactant loses three carbon atoms and one alcohol functionality, leading to an expected increase of $p_{\mathrm{L} \text {,parent }}^{0}$ of 3.5 orders of magnitude, according to the vapour pressure method used in our model (Capouet and Müller, 2006). Since one vapour pressure class spans a $\log \left(p_{\mathrm{L} \text {, parent }}^{0}\right)$ range of 0.5 , the product in our example moves up 7 volatility classes, from class "i" to class " $b$ ". On the other hand, for H-shift isomerisation (Reaction (3) in Table 1) the alkoxy radical abstracts an $\mathrm{H}$-atom from another carbon, leading to a hydroxy alkyl radical (Vereecken and Peeters, 2010). This radical can react with oxygen, forming a peroxy radical ("LX10kO2"), which becomes the explicitly represented group. The alcohol function is included in the implicit part of the generic species, reducing its volatility, so that it moves from class " $i$ " to the lowest vapour pressure class " $k$ ". In case the alkyl radical contains a primary carbonyl functions, after reaction with oxygen it becomes an acyl peroxy radical ("LX10kO3"). If instead it contains an $\alpha$-hydroperoxide, nitrate or alcohol function, it will decompose into an aldehyde. The implicit part of the generic species then loses a functional group, so that product volatility is increased ("LX10gCHO"). For peroxy- and acyl peroxy radicals, the same scheme as for their explicit counterparts is used, where we assign to all alkyl peroxy radicals the reactivity of secondary alkyl peroxy radicals (the "R2R" class defined in Capouet et al., 2008).

The generic chemistry contains the implicit representation of a very large number of chemical reactions which the further generation products are expected to undergo. It is based on choices for rate constants, made on the basis of analogy with other mechanisms, such as the explicit primary chemistry of $\alpha$-pinene. The assumed reactivity of the implicit part of the generic species remains, however, among the largest sources of uncertainty in our model. This uncertainty is explored through sensitivity tests presented in Sects. 2.5 and 3.4.5. 


\subsection{Heterogeneous and aerosol phase chemistry}

Studies have pointed towards the importance of heterogeneous and aerosol phase chemistry. Although the formation of peroxy hemiacetals was investigated in a sensitivity test using BOREAM (Capouet et al., 2008), the reaction rates remain quite uncertain, and this reaction is not part of the current version of BOREAM. Other oligomer forming reactions, such as hemiacetal formation and esterification have been proposed, but the reaction rates of these processes, which often require acid catalysis in the aerosol phase, are still not known (see Hallquist et al. (2009) for an overview). Other studies have focused on $\mathrm{OH}$-oxidation of the aerosol phase (Smith et al., 2009). This process is neglected, as sensitivity tests indicate that it only has a minor impact on SOA yields due to kinetic limitations under atmospheric conditions (Hildebrandt et al., 2010).

In previous modelling studies, the photolysis of species in the aerosol phase was generally ignored, due to a lack of data, and because the further chemistry of radical products in the aerosol is poorly understood. Several recent studies have shown that photolysis of oxygenated organic compounds in the particulate phase is far from negligible. In Mang et al. (2008) the photolysis of carbonyls in limonene SOA was investigated, and estimates of the quantum yield and absorption spectra for the carbonyl compounds in the SOA led to an estimated lifetime of about $6 \mathrm{~h}$ for a zenith angle of $20^{\circ}$. The present model version includes aerosol phase photolysis, with identical J-values and product distributions as in the gas phase, in view of the lack of more reliable experimental data.

\subsection{Partitioning between gas phase and aerosol phase}

The partitioning between aerosol and gas phase is treated as in Ceulemans et al. (2010). It makes use of the absorption theory of Pankow (1994), in which the equilibrium constant $K_{\mathrm{p}, i}=C_{\mathrm{p}, i} / C_{\mathrm{g}, i} \cdot M_{\mathrm{O}}^{-1}$ determines the ratio of the particle and gas phase concentration of species $i$, which is also dependent on the total absorbing organic aerosol mass concentration $M_{\mathrm{O}}\left(\right.$ in $\mu \mathrm{g} \mathrm{m}^{-3}$ ). This partitioning constant can be calculated through the formula

$$
K_{\mathrm{p}, i}=\frac{760 \cdot R T \cdot f_{\mathrm{om}}}{\mathrm{MW}_{\mathrm{om}} \times 10^{6} \cdot \gamma_{i} \cdot p_{\mathrm{L}, i}^{0}}
$$

where $R$ is the gas constant $\left(\operatorname{atm~m} \mathrm{K}^{-1} \mathrm{~mol}^{-1}\right)$; $T$ is temperature $(\mathrm{K}) ; \mathrm{MW}_{\mathrm{om}}$ is the molecular weight of the absorbing medium $\left(\mathrm{g} \mathrm{mol}^{-1}\right) ; f_{\mathrm{om}}$ is the weight fraction of organic matter in the total aerosol; $\gamma_{i}$ is the activity coefficient of compound $i$ in the particulate phase; $p_{\mathrm{L}, i}^{0}$ is its subcooled saturated vapour pressure (here in Torr); 760 (Torr atm ${ }^{-1}$ ) and $10^{6}\left(\mu \mathrm{g} \mathrm{g}^{-1}\right)$ are unit conversion factors. The method of Capouet and Müller (2006) is used to estimate the vapour pressure $p_{\mathrm{L}, i}^{0}$ as a function of temperature for the semi- volatile species present in the BOREAM gas phase mechanism. The activity coefficients $\gamma_{i}$ are calculated online using the method described in Compernolle et al. (2009), covering most relevant atmospheric functional groups. It is an adapted version of UNIFAC (Fredenslund et al., 1975), as formulated by Hansen et al. (1991), and with some parameters determined by Raatikainen and Laaksonen (2005). Water uptake is also considered by the model.

\subsection{Model comparison against photooxidation smog chamber experiments}

Previous simulations of $\alpha$-pinene photooxidation (Capouet et al., 2008) and dark ozonolysis (Ceulemans et al., 2010) smog chamber experiments showed that the BOREAM SOA mass yields generally fall within a factor two of the experimental data. For dark ozonolysis, larger discrepancies were found at high temperatures (above $30^{\circ} \mathrm{C}$ ) and at low VOC loadings and no seed. In this section, the current version of the BOREAM model (updated for generic chemistry, aerosol photolysis, water uptake and non-ideality effects) is evaluated, with a focus on photooxidation experiments, and on experiments in which secondary chemistry through $\mathrm{OH}-$ oxidation or photolysis takes place.

An overview of the simulated experiments is given in Table 2. All experiments made use of a light source. Most experiments also included a considerable quantity of $\mathrm{NO}_{\mathrm{x}}$, except the first experiment of $\mathrm{Ng}$ et al. (2007a), which was conducted under very low- $\mathrm{NO}_{\mathrm{x}}$ conditions, and three of the Presto et al. (2005a) experiments considered. For experiment 1 in $\mathrm{Ng}$ et al. (2007a), unknown quantities of $\mathrm{NO}_{\mathrm{x}}$, $\mathrm{H}_{2} \mathrm{O}_{2}$ and $\mathrm{O}_{3}$ were present at the start of the experiment, which were constrained using the measurements of $\alpha$-pinene and $\mathrm{O}_{3}$ for this experiment, provided in Valorso et al. (2011), following the approach of this last study. For experiment 4 in $\mathrm{Ng}$ et al. (2007a), the HONO concentration and an unknown $\mathrm{OH}$-source were constrained similarly, based on $\alpha$-pinene and $\mathrm{NO}_{\mathrm{x}}$ data (see again Valorso et al., 2011). For the low$\mathrm{NO}_{\mathrm{x}}$ scenario, reasonable agreement is reached for ozone production (see Fig. S2 in the Supplement). For the high$\mathrm{NO}_{\mathrm{x}}$ experiment, reproducing the observed $\alpha$-pinene decay is possible only when an additional $\mathrm{OH}$-source is included, possibly due to reactions on walls, as proposed by Valorso et al. (2011). Reasonable agreement is obtained with measured $\mathrm{NO}$ and $\mathrm{NO}_{2}$ concentrations (see Fig. S5 in the Supplement). However, for one intermediate- $\mathrm{NO}_{\mathrm{x}}$ experiment, serious overestimations of ozone production were found, both in Valorso et al. (2011) and in our study. It is doubtful that SOA yields can be simulated reliably when the model shows such discrepancies for ozone. Therefore we did not include this experiment in the overview in Table 2. SOA yields for this experiment were actually strongly overestimated, as in Valorso et al. (2011). In addition, we show simulations of three experiments of Carter (2000), in which the quantity $D\left(\mathrm{O}_{3}-\mathrm{NO}\right)=\left(\left[\mathrm{O}_{3}\right]-\left[\mathrm{O}_{3}\right]_{\text {initial }}\right)-\left([\mathrm{NO}]-[\mathrm{NO}]_{\text {initial }}\right)$ was 
Table 2. Photooxidation smog chamber experiments simulated with the full BOREAM model.

\begin{tabular}{|c|c|c|c|c|c|c|}
\hline Experiment & $\begin{array}{l}\text { Initial VOC } \\
(\mathrm{ppb})\end{array}$ & $\begin{array}{l}\mathrm{NO}_{\mathrm{x}} \\
(\mathrm{ppb})\end{array}$ & $\begin{array}{c}\text { Temperature } \\
(\mathrm{K})\end{array}$ & $\begin{array}{l}\mathrm{NO}_{2} \text { photolysis } \\
\mathrm{J} \text {-value (in } \mathrm{s}^{-1} \text { ) }\end{array}$ & $\begin{array}{l}\text { Exp. SOA } \\
\text { mass yield }\end{array}$ & $\begin{array}{c}\text { Model SOA } \\
\text { mass yield }\end{array}$ \\
\hline \multicolumn{7}{|c|}{ Ng et al. (2007a) } \\
\hline Exp. 1 & 13.8 & $(0.7)$ & 298 & $5.5 \times 10^{-3}$ & 0.379 & 0.592 \\
\hline Exp. 4 & 12.6 & 938 & 299 & $7.0 \times 10^{-3}$ & 0.066 & 0.070 \\
\hline \multicolumn{7}{|l|}{ Ng et al. (2006) } \\
\hline Exp. 3/9/2005 & 108 & 95 & 293 & $1.1 \times 10^{-3}$ & 0.26 & 0.298 \\
\hline \multicolumn{7}{|c|}{ Presto et al. (2005a) } \\
\hline Exp. 12 & 20.6 & 11 & 295 & $3.0 \times 10^{-2}$ & 0.065 & 0.066 \\
\hline Exp. 15 & 205 & 6.5 & 295 & $3.0 \times 10^{-2}$ & 0.304 & 0.331 \\
\hline Exp. 19 & 156 & 6 & 295 & $3.0 \times 10^{-2}$ & 0.251 & 0.284 \\
\hline Exp. 25 & 10.8 & 20 & 295 & $3.0 \times 10^{-2}$ & 0.026 & 0.019 \\
\hline Exp. 26 & 152 & 9 & 295 & $3.0 \times 10^{-2}$ & 0.224 & 0.278 \\
\hline Exp. 27 & 15 & 14 & 295 & $3.0 \times 10^{-2}$ & 0.057 & 0.040 \\
\hline \multicolumn{7}{|c|}{ Takekawa et al. (2003) } \\
\hline Exp. 1 & 100 & 53 & 283 & $4.0 \times 10^{-3}$ & 0.312 & 0.390 \\
\hline Exp. 2 & 81 & 43 & 283 & $4.0 \times 10^{-3}$ & 0.317 & 0.360 \\
\hline Exp. 3 & 55 & 30 & 283 & $4.0 \times 10^{-3}$ & 0.275 & 0.307 \\
\hline Exp. 4 & 196 & 102 & 303 & $4.0 \times 10^{-3}$ & 0.133 & 0.249 \\
\hline Exp. 5 & 146 & 80 & 303 & $4.0 \times 10^{-3}$ & 0.119 & 0.224 \\
\hline Exp. 6 & 93 & 54 & 303 & $4.0 \times 10^{-3}$ & 0.066 & 0.187 \\
\hline \multicolumn{7}{|c|}{ Nozière et al. (1999) } \\
\hline Exp. 17 & 305 & 3500 & 298 & $3.5 \times 10^{-4}$ & 0.073 & 0.067 \\
\hline Exp. 18 & 1488 & 3300 & 298 & $3.5 \times 10^{-4}$ & 0.306 & 0.314 \\
\hline Exp. 19 & 980 & 4090 & 298 & $3.5 \times 10^{-4}$ & 0.219 & 0.178 \\
\hline Exp. 20 & 330 & 3755 & 298 & $3.5 \times 10^{-4}$ & 0.079 & 0.102 \\
\hline \multicolumn{7}{|c|}{ Hoffmann et al. (1997) } \\
\hline Exp. 3 & 72 & 203 & 315 & $8.3 \times 10^{-3}($ solar $)$ & 0.078 & 0.105 \\
\hline Exp. 4 & 19.5 & 113 & 315 & $8.3 \times 10^{-3}($ solar $)$ & 0.016 & 0.085 \\
\hline Exp. 5 & 53.0 & 206 & 324 & $8.3 \times 10^{-3}($ solar $)$ & 0.037 & 0.038 \\
\hline Exp. 6 & 94.5 & 135 & 321 & $8.3 \times 10^{-3}$ (solar $)$ & 0.086 & 0.068 \\
\hline Exp. 7 & 87.4 & 125 & 321 & $8.3 \times 10^{-3}($ solar $)$ & 0.108 & 0.101 \\
\hline Exp. 8 & 95.5 & 124 & 316 & $8.3 \times 10^{-3}($ solar $)$ & 0.102 & 0.101 \\
\hline Exp. 9 & 94.6 & 122 & 316 & $8.3 \times 10^{-3}($ solar $)$ & 0.089 & 0.101 \\
\hline
\end{tabular}

determined experimentally. The current BOREAM model version shows good agreement or slight overestimation of ozone production for these experiments (see Figs. S7 to S9 in the Supplement).

In $\mathrm{Ng}$ et al. (2007a) an aerosol density of $1.32 \mathrm{~g} \mathrm{~cm}^{-3}$ was measured, which was used to derive the experimental mass yields, based on the experimentally determined aerosol volume concentrations. A density of $1.25 \mathrm{~g} \mathrm{~cm}^{-3}$ was used by $\mathrm{Ng}$ et al. (2006). In all other studies considered, measured SOA volume concentrations were transformed into mass concentrations based on an assumed aerosol density of
$1.0 \mathrm{~g} \mathrm{~cm}^{-3}$. Since this estimate is likely too low, in view of the measurement of $\mathrm{Ng}$ et al. (2007a), we have multiplied the reported SOA mass yields by a factor of 1.32 .

In Fig. 1, SOA mass yields from smog chamber experiments are compared with yields for simulations of these experiments with the full BOREAM model. For most experiments, the SOA yields are reproduced well within a factor of 2. In some experiments, such as Takekawa et al. (2003) and Hoffmann et al. (1997), there is a considerable ozone production, so that part of the $\alpha$-pinene undergoes ozonolysis. A small part of the large overestimations (more than a factor 2) 


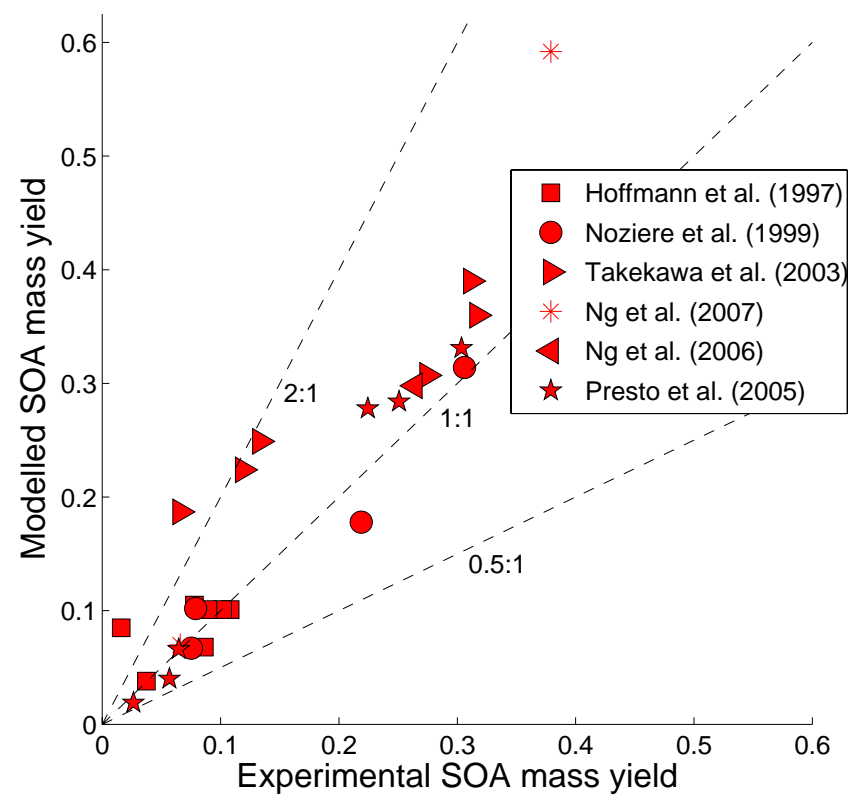

Fig. 1. Measured versus modelled aerosol mass yields for the $\alpha$ pinene photooxidation smog chamber experiments reported in Table 2 .

found for three experiments of Takekawa et al. (2003) might be related to uncertainties regarding the yield of carboxylic acids, such as pinic and hydroxy pinonic acid, which are formed in $\alpha$-pinene ozonolysis, but for which the formation mechanism is not well understood (Ceulemans et al., 2010). Their production yield is held fixed in the model, although it is very probably dependent on photochemical conditions, e.g. the $\mathrm{NO}_{\mathrm{x}}$ abundance. Pinic acid is found to represent about $8 \%$ of the SOA in the experiments of Takekawa et al. (2003) at $303 \mathrm{~K}$. Therefore errors in pinic acid production alone cannot explain much of the model overestimates. Most species in the SOA in these experiments bear a peroxy acetyl nitrate group. Uncertainties regarding the formation and decomposition of such species could therefore be responsible for part of the model overestimates. The model reproduces well the SOA decrease with increasing $\mathrm{NO}_{\mathrm{x}}$ concentrations, as seen from the comparison of experiments 1 and 4 of $\mathrm{Ng}$ et al. (2007a), for which the time evolution is given in Figs. S3 and S6 in the Supplement. The SOA yield in the low- $\mathrm{NO}_{\mathrm{x}}$ experiment 1 of $\mathrm{Ng}$ et al. (2007a) is overestimated by the model, a result which was also obtained in Valorso et al. (2011). Overall the model results agree reasonably well with the experimental values, considering the theoretical and experimental uncertainties.

Figure 2 shows the sensitivity of calculated SOA to changes in the values of key parameters in the generic chemistry scheme of the BOREAM model, such as the assumed value for " $k_{\mathrm{LX}}$ ", the reactivity towards $\mathrm{OH}$ (see Table S1.2.1 in the Supplement), and the J-value " $j_{\text {LXALD" }}$ " of the generic part of the generic species (see Table S1.2.2 in the Supple- ment). The tests show that their impact on simulated SOA mass yields is limited for both the low- and high- $\mathrm{NO}_{\mathrm{x}}$ experiments 1 and 4 of $\mathrm{Ng}$ et al. (2007a). Tests in which the branching ratios of alkoxy radicals towards decomposition and $\mathrm{H}$-shift isomerisation are varied, show that these have a larger impact on predicted SOA in the high- $\mathrm{NO}_{\mathrm{x}}$ case. A test in which $100 \%$ of alkoxy radicals undergo H-shift isomerisation leads to a large increase of predicted SOA yields. However this assumption is most likely not realistic, and even an assumed branching ratio of $50 \%$ of $\mathrm{H}$-shift might be on the high side. In that case there is still a significant increasing effect on SOA yields. There are two main reasons for the higher sensitivity of SOA yields to the branching of alkoxy radicals under high- $\mathrm{NO}_{\mathrm{x}}$ conditions than for low$\mathrm{NO}_{\mathrm{x}}$. Firstly, under high- $\mathrm{NO}_{\mathrm{x}}$ conditions peroxy radicals react predominantly with $\mathrm{NO}$, forming mostly alkoxy radicals, whereas under low- $\mathrm{NO}_{\mathrm{x}}$ conditions they react mostly with $\mathrm{HO}_{2}$, generally leading to other products. Secondly, in our simulations the volatility of products is generally higher under high- $\mathrm{NO}_{\mathrm{x}}$ conditions. Since a given shift in volatility generally has a larger impact on partitioning for semi-volatile products, which are still present in significant quantities in both phases, than for low-volatile products, which reside already for a large fraction in the particulate phase, it is expected that the change in volatility due to alkoxy radical branching affects SOA yields more in high- $\mathrm{NO}_{\mathrm{x}}$ conditions. Addressing the uncertainty of the generic chemistry scheme would require characterising more explicitly the species corresponding to the different generic species classes, for example with the help of a self-generating mechanism approach such as used in Valorso et al. (2011). Structure activity relationships for alkoxy radicals such as those in Vereecken and Peeters (2009) and Vereecken and Peeters (2010) can then be used to obtain a more thorough estimate of the alkoxy radical branching for generic species.

\section{Parameterised SOA formation model based on BOREAM}

\subsection{Parameter model}

In contrast to previous mechanism reduction studies (e.g. Xia et al., 2009), which aimed at reproducing the impact of the precursor VOC not only on SOA formation but also on the concentrations of oxidants and several key gaseous compounds, we limit the scope of our parameterisation to SOA formation as modelled by BOREAM in typical atmospheric conditions. For this purpose, we adopt the commonly used two-product model first applied by Odum et al. (1996), except that the parameters are obtained from box model simulations with BOREAM, and that the parameterisation accounts for the dependence of SOA yields on the nature of the oxidant $\left(\mathrm{OH}, \mathrm{O}_{3}\right.$ or $\left.\mathrm{NO}_{3}\right)$ and on the abundance of $\mathrm{NO}$. This leads us to consider 5 different scenarios: $\mathrm{OH}$-oxidation 


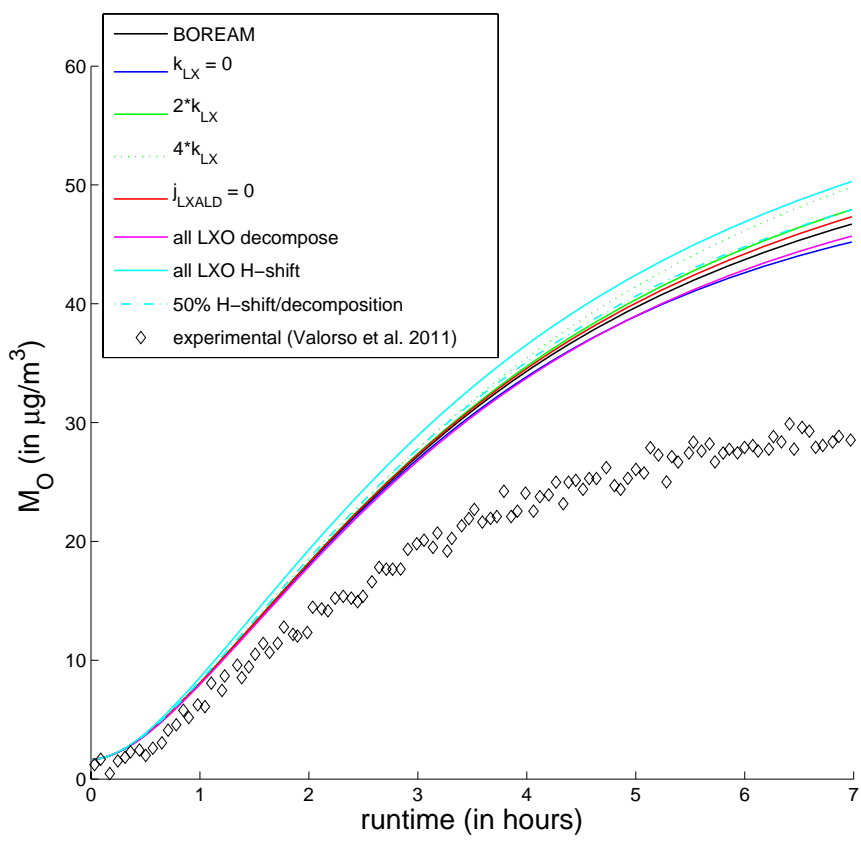

(a) Exp. 1, Ng et al. (2007a)

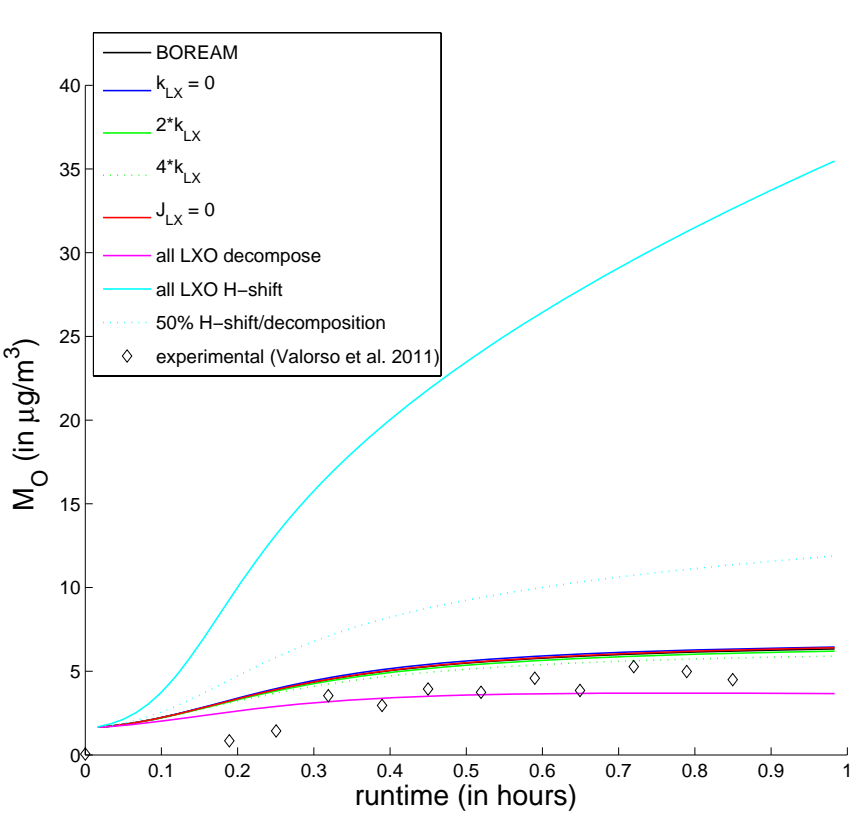

(b) Exp. 4, Ng et al. (2007a)

Fig. 2. Time evolution for the Experiments 1 (low- $\mathrm{NO}_{\mathrm{x}}$ ) and 4 (high- $\mathrm{NO}_{\mathrm{x}}$ ) of $\mathrm{Ng}$ et al. (2007a), based on data presented in Valorso et al. (2011). Shown are sensitivity tests for SOA yields to the assumed reaction constant with $\mathrm{OH}$ of the generic part of generic species classes, $k_{\mathrm{LX}}$, the J-value $j_{\mathrm{LXALD}}$ of this generic part and the branching ratios of generic alkoxy radicals.

and ozonolysis, both for low and high- $\mathrm{NO}_{\mathrm{x}}$, and high- $\mathrm{NO}_{\mathrm{x}}$ $\mathrm{NO}_{3}$-oxidation. It is found that in each case 2 condensable products suffice to parameterise SOA-formation, thus leading to a model containing in total 10 condensable products.

In the original two-product model, oxidation of the SOA precursor leads to the immediate formation of two surrogate compounds, with mass-stoichiometric coefficients $\left(\alpha_{i}\right)$ and partitioning constants $\left(K_{\mathrm{p}, i}\right)$ adjusted in order to reproduce a set of experimental SOA yields, through the equation

$Y=\sum Y_{i}=M_{\mathrm{O}} \sum \frac{\alpha_{i} K_{\mathrm{p}, i}}{1+K_{\mathrm{p}, i} \cdot M_{\mathrm{O}}}$

where $Y$ is the SOA mass yield. Note that the molar stoichiometric coefficients $\alpha_{i}^{\prime}$ can be derived from the mass-stoichiometric coefficients and the ratio of the molar mass of the precursor and the organic aerosol: $\alpha_{i}^{\prime}=$ $\mathrm{MW}_{\alpha \text {-pinene }} / \mathrm{MW}_{\mathrm{OA}} \cdot \alpha_{i}$. In order to account for the large influence of the $\mathrm{NO}_{\mathrm{x}}$-regime on SOA yields (see for example Presto et al., 2005b or Capouet et al., 2008), the VOC oxidation product can be taken to be a peroxy radical ("PRAPOH1" and "PRAPO31", see Table 3), which upon reaction with $\mathrm{NO}$ or $\mathrm{HO}_{2}$, leads to a set of condensable products with stoichiometric and partitioning coefficients adjusted against experiments conducted under high or low NO conditions respectively. This system, adopted by Henze et al. (2008) to parameterise $\mathrm{NO}_{\mathrm{x}}$-dependence of SOA yields for aromatic compounds, is also used here, although modified with the introduction of an additional peroxy radi- cal ("PRAPOH2" or "PRAPO32" in Table 3), in order to better reproduce the $\mathrm{NO}_{\mathrm{x}}$-dependence of the yields at intermediate NO levels, as described in more detail in Sect. 3.4.1. The reduced mechanism of our parameterisation is presented in Table 3. We made the assumption that under low- $\mathrm{NO}_{\mathrm{x}}$ conditions, $\mathrm{NO}_{3}$ concentrations will also be low, and that therefore the oxidation of $\alpha$-pinene will be dominated by $\mathrm{OH}$ or ozone. Only under high- $\mathrm{NO}_{\mathrm{x}}$ conditions would there be a more considerable SOA production due to $\mathrm{NO}_{3}$. Therefore for $\mathrm{NO}_{3}$ it was sufficient to parameterise the high- $\mathrm{NO}_{\mathrm{x}}$ case only, removing the need for intermediate peroxy radicals which regulate the branching between high- and low- $\mathrm{NO}_{\mathrm{x}}$ products in that case. Although the cross-reactions of peroxy radicals are ignored in the reduced mechanism, their role is taken into account in the full BOREAM model. This simplification is not expected to cause large errors, except in the case of very high VOC loadings. Additionally for each condensable product, a pseudo-photolysis reaction is introduced, which accounts for chemical processing of the condensable products, as will be explained in more detail in the next section. The parameterisation includes a total of 21 equations and 10 condensable products.

\subsection{Scenarios for full model runs}

The parameter model is fitted to full BOREAM model simulations conducted under five scenarios, each corresponding to one pair of products. We limit the oxidation of $\alpha$-pinene to 
Table 3. Chemical mechanism of the parameter model.

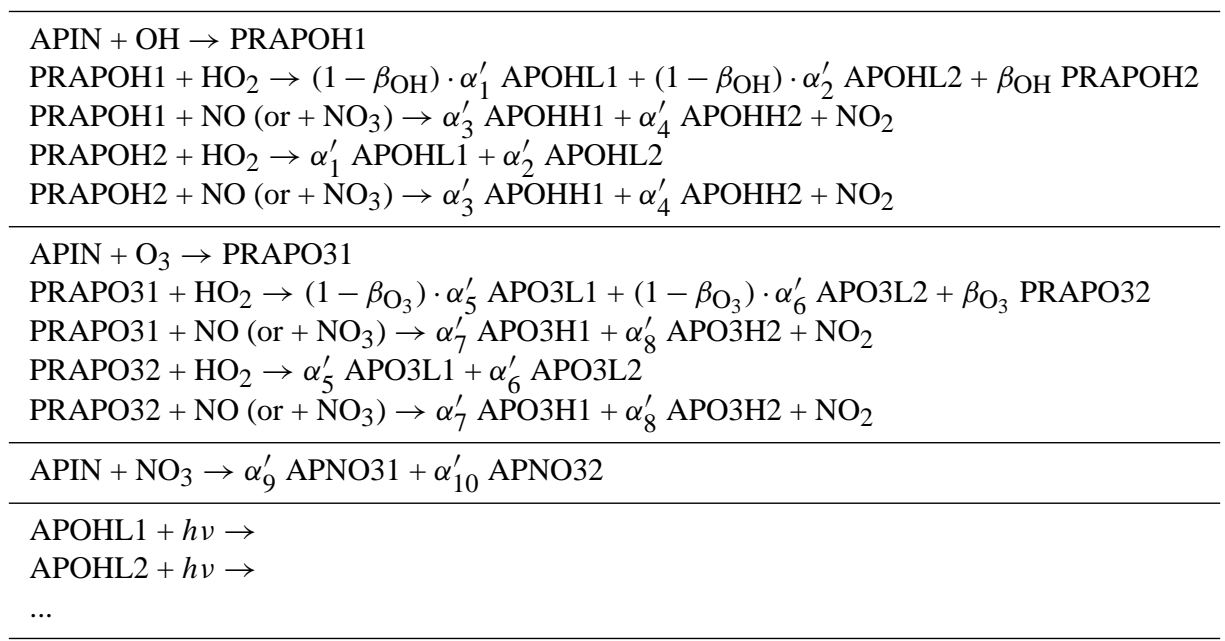

one oxidant, by turning off the reactions with the other two main oxidants. All oxidants, however, are allowed to react with the oxidation products of $\alpha$-pinene. For the high- $\mathrm{NO}_{\mathrm{x}}$ scenario we adopt a concentration of $100 \mathrm{ppb} \mathrm{NO}_{2}$, while for the low- $\mathrm{NO}_{\mathrm{x}}$ scenario we take 1 ppt of $\mathrm{NO}_{2}$.

In order to mimic real atmospheric conditions, where SOA is composed of a mix of fresh and aged material, subject to wet and dry deposition, we conduct BOREAM simulations including a sustained emission of $\alpha$-pinene, as well as a sink of gaseous and particulate compounds due to dilution and deposition. Adopting a sink term corresponding to a lifetime of 6 days, typical for organic aerosols (see for example Farina et al., 2010), as well as prescribed diurnal cycles for the photolysis rates and for the concentrations of $\mathrm{OH}, \mathrm{HO}_{2}, \mathrm{O}_{3}, \alpha$-pinene and $\mathrm{NO}_{2}$, the system approaches a quasi-steady-state in about 12 days (see the black curve in Fig. 3a and b). The noontime photolysis rates are calculated by assuming a $20^{\circ}$ zenith angle. Their diurnal variation is assumed to follow a $\sin ^{2}$ function zeroing at 05:00 a.m. and 07:00 p.m. LT, corresponding to summertime conditions at mid-latitudes. The concentrations of $\mathrm{OH}$ and $\mathrm{HO}_{2}$ are kept constant during the night, at $2 \times 10^{5}$ and $10^{8} \mathrm{~cm}^{-3}$, respectively, whereas their noontime (maximum) values are set to $10^{7}$ and $2 \times 10^{9} \mathrm{~cm}^{-3}$, respectively. These values are in the range of concentrations reported from field measurements, e.g. Hofzumahaus et al. (2009) in the Pearl River Delta, Martinez et al. (2003) around Nashville, and Martinez et al. (2010) in the Surinam rainforest.

Ozone concentrations are also prescribed, and follow a diurnal cycle. For high- $\mathrm{NO}_{x}$ scenarios or when $\mathrm{O}_{3}$ is the main oxidant, the night-time concentrations are assumed to be $15 \mathrm{ppb}$, and during the day they follow the diurnal cycle, reaching a maximum value of $60 \mathrm{ppb}$. In low- $\mathrm{NO}_{\mathrm{x}}$ conditions, and when $\mathrm{OH}$ is the oxidant, ozone concentrations typical of unpolluted areas are chosen with $5 \mathrm{ppb}$ at night and $15 \mathrm{ppb}$ at the daytime maximum. A series of runs with increasing VOC concentrations is then performed, in order to cover a range of organic aerosol loadings between about 0.1 and $50-100 \mu \mathrm{g} \mathrm{m}^{-3}$, at seven temperatures between $273 \mathrm{~K}$ and $303 \mathrm{~K}$, with steps of $5 \mathrm{~K}$. Water uptake to the aerosol phase is suppressed in these runs. The additional SOA formation due to water uptake will be parameterised through activity coefficients, as documented in Sect. 3.6. When SOA has reached an equilibrium state in the full model $\mathrm{OH}$-oxidation scenarios, SOA typically keeps varying diurnally with a maximum value in the afternoon, a few hours after both $\alpha$-pinene and $\mathrm{OH}$ concentrations have reached a peak value. Later on SOA concentrations go down due to photochemical losses, deposition and the weakening of photochemical production.

For each simulation, the quasi-steady state SOA mass yield is calculated from the model results on the 13th day of the simulation, with $Y=\Delta[\mathrm{OA}]_{\text {prod. }} / \Delta[\alpha$-pinene $]$, where $\Delta[\alpha$-pinene $]$ is the amount of $\alpha$-pinene oxidised during one day, and $\Delta[\mathrm{OA}]_{\text {prod. }}$ represents the amount of condensable products produced from this amount of oxidised $\alpha$ pinene which contributes to the SOA. Assuming equilibrium, $\Delta[\mathrm{OA}]_{\text {prod. }}$ should equal $\Delta[\mathrm{OA}]_{\text {lost }}$, the amount of organic aerosol which is lost due to mainly two processes. A first sink is the loss through deposition during one day, which equals the daily averaged aerosol concentration divided by the deposition lifetime in days.

A second important contribution is the degradation of the condensable products due to photochemical reactions and photolysis. This includes the oxidation and photolysis of gaseous products at equilibrium with the SOA components, as well as the photolysis of particulate compounds. Simulations with the full BOREAM model in which, starting from day 13 , both $\alpha$-pinene oxidation and product deposition are switched off, show that the combined effect of photolysis and reactions with oxidants leads to a decrease of SOA concentrations, both under low and high- $\mathrm{NO}_{\mathrm{x}}$ conditions (see the red curves in Fig. 3a and b). This result might seem contrary 


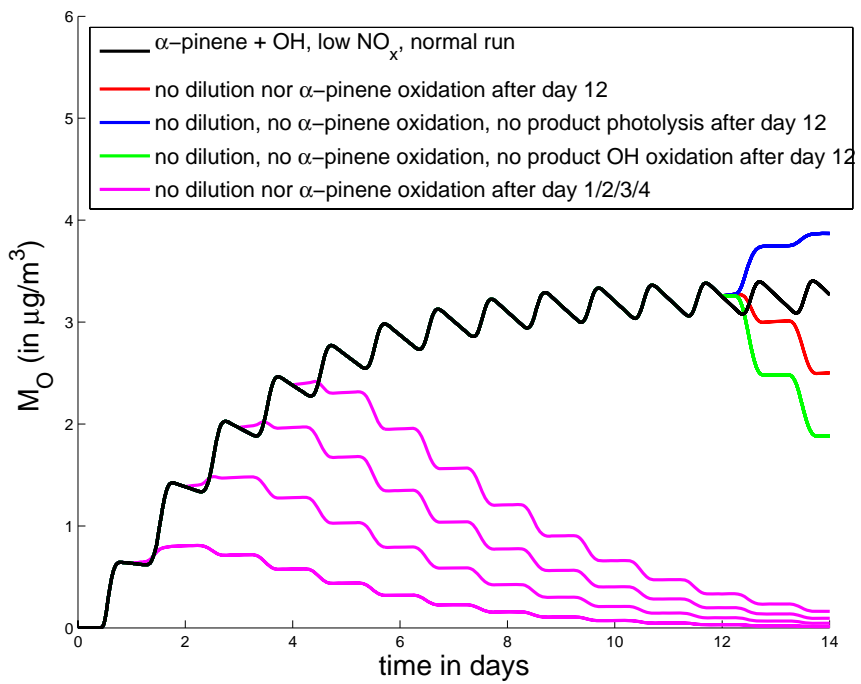

(a) low- $\mathrm{NO}_{\mathrm{x}} \mathrm{OH}$-oxidation $(273 \mathrm{~K})$

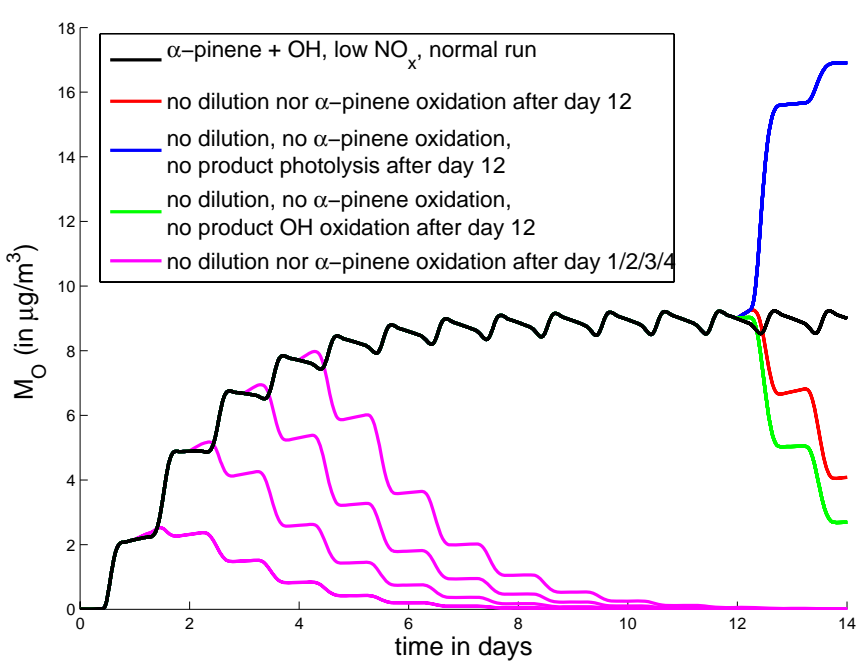

(b) high- $\mathrm{NO}_{\mathrm{x}} \mathrm{OH}$-oxidation $(273 \mathrm{~K})$

Fig. 3. Full BOREAM model SOA mass loading $M_{\mathrm{O}}$, for the low- $\mathrm{NO}_{\mathrm{x}}$ and high- $\mathrm{NO}_{\mathrm{x}} \mathrm{OH}-\mathrm{oxidation}$ scenario, at $273 \mathrm{~K}$, as a function of time (black). $\alpha$-pinene concentrations undergo a diurnal variation between $0.002 \mathrm{ppb}$ at night and $0.01 \mathrm{ppb}$ as the maximum during the day for low- $\mathrm{NO}_{\mathrm{x}}$, and between 0.02 and $0.1 \mathrm{ppb}$ for high- $\mathrm{NO}_{\mathrm{x}}$. When $M_{\mathrm{O}}$ has reached a stable equilibrium level, a number of tests are conducted, starting after day 12, to estimate the impact of photo-chemical reactions on the condensable products without further $\alpha$-pinene oxidation and product deposition. Similar tests show the effect of photo-chemical reactions at earlier points in the ageing scenario, starting after 1,2 , 3 or 4 days (magenta).

to the finding from experimental studies (e.g. Jimenez et al., 2009; Docherty and Ziemann, 2003) that photochemical ageing can have an increasing effect on SOA concentrations. In Lambe et al. (2011) SOA yields for $\alpha$-pinene photooxidation were observed to be first increasing with increasing $\mathrm{OH}$ exposure time, but after reaching a maximum value SOA yields began decreasing when photochemical ageing was continued. It should be noted that in Lambe et al. (2011) UV-light was applied, therefore it remains to be verified whether a similar behaviour would take place with solar radiation, as in our photo-chemical ageing simulations.

However, in the present simulations SOA material is already photochemically aged at the onset of the test. Tests in which only photolysis reactions or only $\mathrm{OH}$ reactions take place after day 12 show that, taken separately, these processes have a decreasing respectively increasing effect on the SOA levels. When these reactions take place together, their combined effect is to decrease the SOA concentration. It also is apparent from the tests shown in Fig. 3a and b that, especially at high- $\mathrm{NO}_{\mathrm{x}}$, superimposing the separate effects of photolysis and $\mathrm{OH}$ reactions on SOA concentrations does not reproduce exactly the combined effect of photolysis and $\mathrm{OH}$ reactions acting simultaneously on SOA products. We have performed similar tests for the effect of photo-chemical reactions on SOA concentrations when $\alpha$-pinene oxidation and deposition of products have been turned off after an earlier time period than 12 days. We have added graphs for these tests to Fig. 3a and b. For low-NO $\mathrm{N}_{\mathrm{x}}$, when $\alpha$-pinene oxidation/deposition is turned off after 1 or 2 days of ageing, there is first a slight increase in SOA concentration due to the reactions with $\mathrm{OH}$ and photolysis of the remaining oxidation products. However, when $\alpha$-pinene oxidation/deposition is turned off after 4 days of $\alpha$-pinene oxidation, the material is more aged. In this case a slight decrease in SOA is obtained due to the combined effect of photochemical reactions on the oxidation products. For high- $\mathrm{NO}_{\mathrm{x}}$, the combined photochemical reactions and photolysis leads to a decrease in SOA even when $\alpha$-pinene oxidation and deposition are shut down after 2 days.

We estimate the net amount of SOA lost during one day due to photochemical processes, which we will call the photochemical OA loss, $[\mathrm{OA}]_{\mathrm{pl}}$. The correct SOA yield is then $\left(\Delta[\mathrm{OA}]_{\text {dep. }}+\Delta[\mathrm{OA}]_{\mathrm{pl}}\right) / \Delta[\alpha$-pinene $]$. Note that it would have been possible to neglect the photochemical OA loss and define a yield based solely on the estimated deposition loss. In such case, the only sink of the (gaseous + particulate) semi-volatile products in the parameterisation is deposition. Although such model would be able to match the SOA concentration of the full model at equilibrium, it would underestimate the SOA concentrations before the onset of this equilibrium, when the photochemical production of condensable compounds greatly exceeds the losses. Using the above formula for calculating the SOA yield, the additional production must be balanced in the parameterisation by an additional sink besides deposition. We therefore incorporate a pseudophotolysis reaction of the condensable products in the parameter model, with a photorate $J_{\mathrm{pl}}$ which is adjusted based on the amount of photochemically lost material estimated 
Table 4. Fitted parameters for the 10 condensable products in the temperature-dependent parameter model ( 5 scenarios considered).

\begin{tabular}{|c|c|c|c|c|c|c|}
\hline Scenario & Product & $\alpha_{i}^{0}$ & $\alpha_{i}^{1}$ & $\begin{array}{l}K_{\mathrm{p}, i}(298 \mathrm{~K}) \\
\left(\mathrm{m}^{3} \mu \mathrm{g}^{-1}\right)\end{array}$ & $\begin{array}{l}\Delta H_{i} \\
\left(\mathrm{~kJ} \mathrm{~mol}^{-1}\right)\end{array}$ & $\begin{array}{l}\mathrm{MW}_{\text {ref }} \\
\left(\mathrm{g} \mathrm{mol}^{-1}\right)\end{array}$ \\
\hline \multirow[t]{2}{*}{$\alpha$-pinene $+\mathrm{OH}$, low- $\mathrm{NO}_{\mathrm{x}}$} & APOHL1 & 0.621 & -0.01229 & 5.4786 & 103.2 & 218.4 \\
\hline & APOHL2 & 0.347 & -0.01532 & 0.1284 & 20.25 & 218.4 \\
\hline \multirow[t]{2}{*}{$\alpha$-pinene $+\mathrm{OH}$, high- $\mathrm{NO}_{\mathrm{x}}$} & APOHH1 & 0.134 & -0.0284 & 0.6769 & 82.9 & 252.6 \\
\hline & APOHH2 & 0.295 & -0.0300 & 0.01300 & 35.8 & 252.6 \\
\hline \multirow[t]{2}{*}{$\alpha$-pinene $+\mathrm{O}_{3}$, low- $\mathrm{NO}_{\mathrm{x}}$} & APO3L1 & 0.566 & -0.0143 & 6.18 & 87.6 & 214.7 \\
\hline & APO3L2 & 0.326 & -0.01637 & 0.0152 & 77.9 & 214.7 \\
\hline \multirow[t]{2}{*}{$\alpha$-pinene $+\mathrm{O}_{3}$, high- $\mathrm{NO}_{\mathrm{x}}$} & APO3H1 & 0.1195 & -0.0342 & 0.557 & 81.9 & 237.6 \\
\hline & $\mathrm{APO} 3 \mathrm{H} 2$ & 0.505 & -0.01312 & 0.00888 & 61.5 & 237.6 \\
\hline \multirow[t]{2}{*}{$\alpha$-pinene $+\mathrm{NO}_{3}$, high- $\mathrm{NO}_{\mathrm{x}}$} & APNO31 & 0.0336 & -0.0657 & 1.043 & 157.7 & 246.9 \\
\hline & APNO32 & 0.252 & -0.01258 & 0.00580 & 116.2 & 246.9 \\
\hline
\end{tabular}

from full BOREAM model runs. For each scenario, the same photolysis rate is applied to both condensable compounds of the two-product model, in the gaseous and in the particulate phases. The procedure for estimating $[\mathrm{OA}]_{\mathrm{pl}}$ and the temperature-dependent fitting of the photorates for each oxidation scenario is described in more detail in the Supplement, Sect. S3. Since our model scenarios used maximum photolysis rates calculated assuming a $20^{\circ}$ solar zenith angle, extrapolation of the SOA photolysis rate to any radiative condition is made by scaling the retrieved maximum photorate with the photolysis rate of higher aldehydes: $J_{\mathrm{pl}}=$ $f_{\mathrm{pl}, \text { max }} \cdot J_{\mathrm{ald}}$ with $f_{\mathrm{pl}, \text { max }}=J_{\mathrm{pl}, \text { max }} / J_{\mathrm{ald}, \text { max }}$ where $J_{\mathrm{pl} \text {,max }}$ and $J_{\text {ald,max }}$ are the pseudo-photolysis rate for chemical loss of SOA and photolysis rate of higher aldehydes, respectively, at the maximum $20^{\circ}$ solar zenith angle in our model scenarios. For each of the 5 oxidation scenarios considered, we then derive a temperature-dependent fit for the functions $f_{\mathrm{pl}, \max }$ (see Table S9 in the Supplement).

In order to take the temperature sensitivity of the yields into account, $Y\left(M_{\mathrm{O}}\right)$ curves are obtained at seven temperatures between $273 \mathrm{~K}$ and $303 \mathrm{~K}$. We assume the following temperature dependence for the partitioning constant:

$K_{\mathrm{p}, i}(T)=K_{\mathrm{p}, i}\left(T_{\mathrm{r}}\right) \frac{T}{T_{\mathrm{r}}} \exp \left(\frac{\Delta H_{i}}{R}\left(\frac{1}{T}-\frac{1}{T_{\mathrm{r}}}\right)\right) \frac{\mathrm{MW}}{\mathrm{MW}_{\text {ref }}}$

in which the reference temperature $T_{\mathrm{r}}=298 \mathrm{~K}, \Delta H_{i}$ represents the enthalpy of vapourisation and $\mathrm{MW}_{\text {ref }}$ is the reference average molar mass of the molecules in the SOA. This approach (Eq. 3) was followed by Saathoff et al. (2009) for obtaining temperature-dependent coefficients for $\alpha$-pinene dark ozonolysis experiments over a wide range of temperatures.

The values for $\mathrm{MW}_{\text {ref }}$ are chosen per oxidation scenario, at a temperature of $298 \mathrm{~K}$ and for an $\alpha$-pinene concentration leading to an equilibrium SOA concentration around $2.5 \mu \mathrm{g} \mathrm{m}^{-3}$. In simulations with the full model at other temperatures and $\alpha$-pinene concentrations, MW varies by not more than roughly $5 \%$ from this reference value. In the full model the average MW of SOA is calculated based on the molecular masses of the explicit species and on estimates for the generic species classes. Equation (3) can be rewritten as $K_{\mathrm{p}, i}(T)=A_{i} \cdot T \cdot \exp \left(\frac{B_{i}}{T}\right)$, where $A_{i}$ and $B_{i}$ are the fitting parameters. For the mass stoichiometric coefficient, a temperature dependence of the form

$\alpha_{i}(T)=\alpha_{i}^{0} \exp \left(\alpha_{i}^{1}\left(T-T_{\mathrm{r}}\right)\right)$

is assumed. The parameterisations are obtained by minimising the relative difference between the full model yields and the yields calculated using Eq. (2). In Table 4, the fitted parameters for the ten products considered are given.

\subsection{Parameter adjustment results}

We compare the evolution of $M_{\mathrm{O}}$ over time between the full model and the parameter model both during the build-up of SOA and when an equilibrium for SOA is approximately reached in all the previously described scenario simulations. The parameter adjustment focussed on achieving a reasonable agreement over the range of $0.5-20 \mu \mathrm{g} \mathrm{m}^{-3}$ for $M_{\mathrm{O}}$. We show the time evolution of SOA in simulations for $\mathrm{OH}$ oxidation under low- $\mathrm{NO}_{\mathrm{x}}$ and high- $\mathrm{NO}_{\mathrm{x}}$ conditions, and an example for $\mathrm{NO}_{3}$ oxidation at high- $\mathrm{NO}_{\mathrm{x}}$ in Fig. 4. In these three cases, the parameter model approaches the full model SOA levels near the end of the simulations, when an equilibrium state is reached. Over the whole range of the time evolution, the parameter model's skill at reproducing SOA concentrations is more variable. For the low- $\mathrm{NO}_{\mathrm{x}} \mathrm{OH}$ oxidation shown here, the time evolution can be considered satisfactory. However, for the oxidation by $\mathrm{NO}_{3}$, it was often not possible to achieve a more accurate time evolution over the whole time scale than the one shown in the example in Fig. 4, featuring significant underestimations during the first days.

In order to provide a measure of how well both models agree in these simulations, we define a deviation factor equal to $\exp \left(\left|\log \left(\overline{M_{\mathrm{O}, \mathrm{p}}} / \overline{M_{\mathrm{O}, \mathrm{f}}}\right)\right|\right)$, where $\overline{M_{\mathrm{O}, \mathrm{p}}}$ and $\overline{M_{\mathrm{O}, \mathrm{f}}}$ are the daily averaged $M_{\mathrm{O}}$ concentrations in the parameterisation and in the full model, respectively. The values of this deviation factor are summarised in Table S10 in the Supplement. 


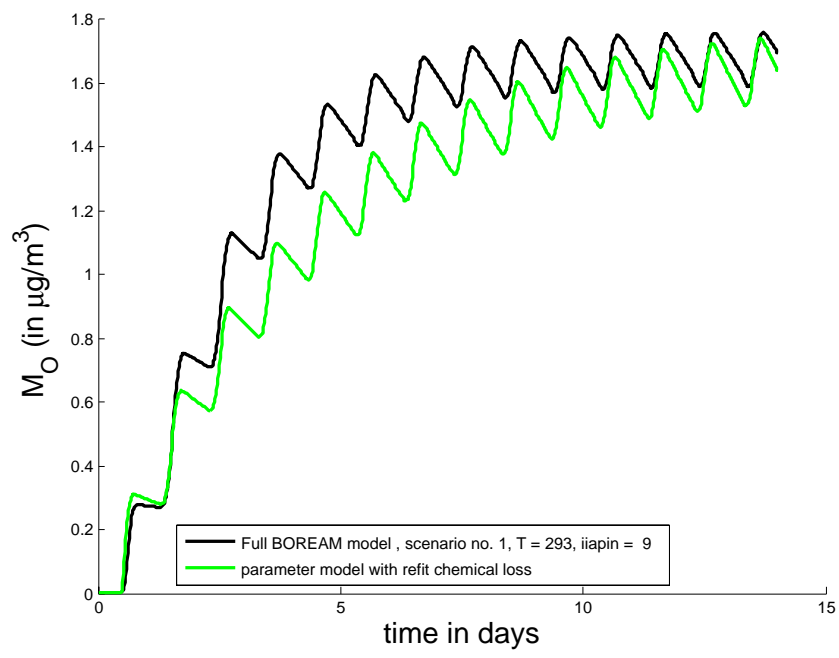

(a) low- $\mathrm{NO}_{\mathrm{X}} \mathrm{OH}$-oxidation $(293 \mathrm{~K})$

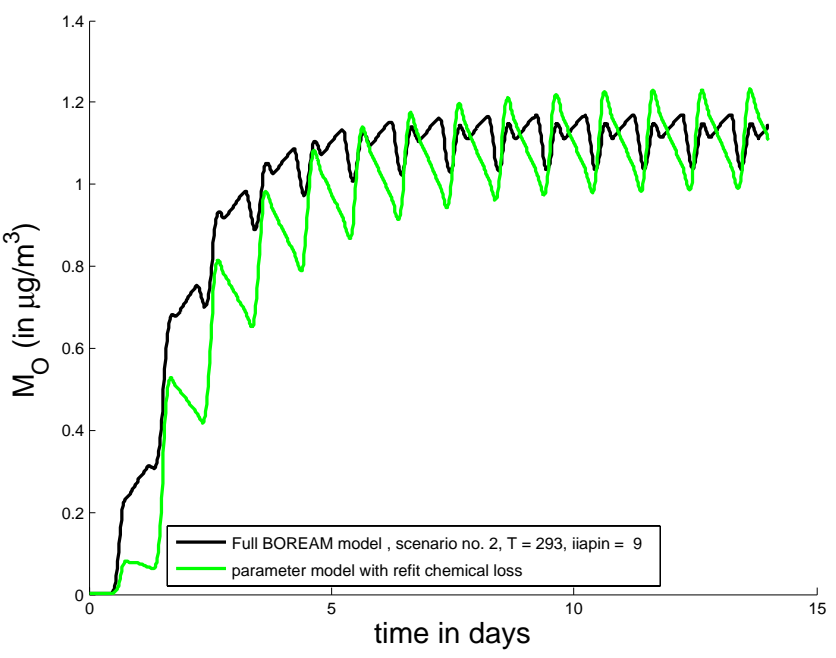

(b) high- $\mathrm{NO}_{\mathrm{x}} \mathrm{OH}$-oxidation $(293 \mathrm{~K})$

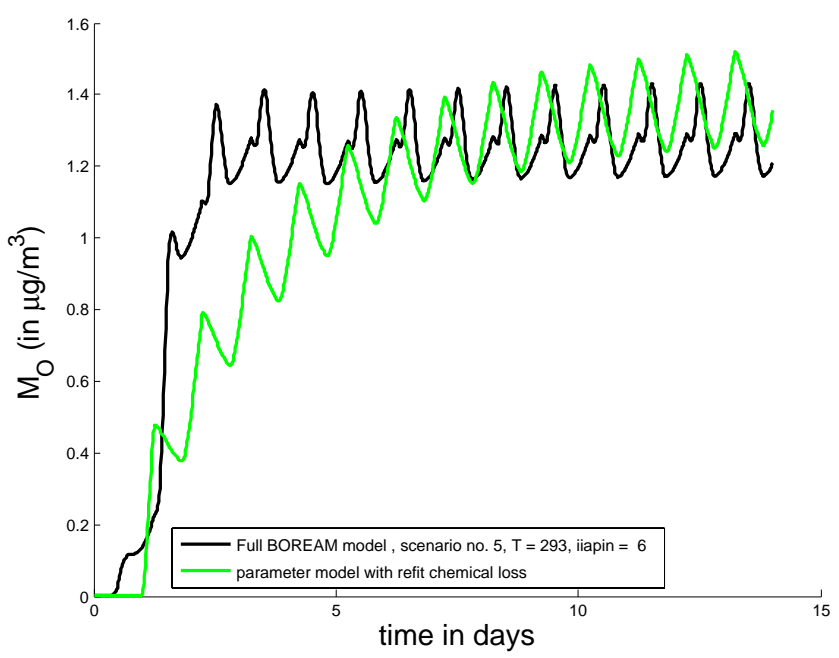

(c) high- $\mathrm{NO}_{\mathrm{x}} \mathrm{NO}_{3}$-oxidation $(293 \mathrm{~K})$

Fig. 4. Time evolution of $M_{\mathrm{O}}$ for three examples of the simulations of $\alpha$-pinene oxidation. The full model results are given in black and the parameter model results in green.

To compare SOA yields between full and reduced model at SOA equilibrium, we also calculate a net SOA yield at equilibrium, using the formula $Y_{\text {net }}=\Delta[\mathrm{OA}]_{\text {dep. }} / \Delta[\alpha$-pinene $]$. In this way only the net amount of OA produced is considered, equal to the amount lost to deposition over one day near equilibrium. We show plots of $Y_{\text {net }}$ versus $M_{\mathrm{O}}$ near SOA equilibrium for the five scenarios and the seven temperatures considered (see Fig. 5).

As can be seen from the SOA deviation factors, agreement is good in the large majority of cases, both during SOA buildup and at SOA equilibrium. For the highest temperatures, and especially in the $\mathrm{NO}_{3}$-oxidation case, it is found more difficult to obtain a good agreement over the whole time period of the SOA build-up in the scenarios. In a few cases at low $M_{\mathrm{O}}$ concentrations (below $0.5 \mu \mathrm{g} \mathrm{m}^{-3}$ ) and at high temperatures,
SOA concentrations are strongly underestimated during the build-up of the SOA (explaining the number of deviations larger than a factor 2 in Table S10 of the Supplement), although by the time the SOA reaches an equilibrium concentration both models agree better (see Fig. 5).

Figure 6 shows the parameterised (dashed lines) and full model (full lines) $Y\left(M_{\mathrm{O}}\right)$ curves at $298 \mathrm{~K}$ between 0 and $20 \mu \mathrm{g} \mathrm{m}^{-3}$. The yields in both low- $\mathrm{NO}_{\mathrm{x}}$ scenarios are about a factor 10 higher than the high- $\mathrm{NO}_{\mathrm{x}}$ yields. The reduction of SOA yields at high- $\mathrm{NO}_{\mathrm{x}}$ has been observed in several previous experimental studies, such as Presto et al. (2005a). The yields for the $\mathrm{OH}$-oxidation of $\alpha$-pinene are found to be somewhat higher than for ozonolysis at low $\mathrm{NO}_{\mathrm{x}}$. The yield curves for the high- $\mathrm{NO}_{\mathrm{x}}$ scenarios lie close to each other, and their maximum in this range is about $3-4 \%$. 


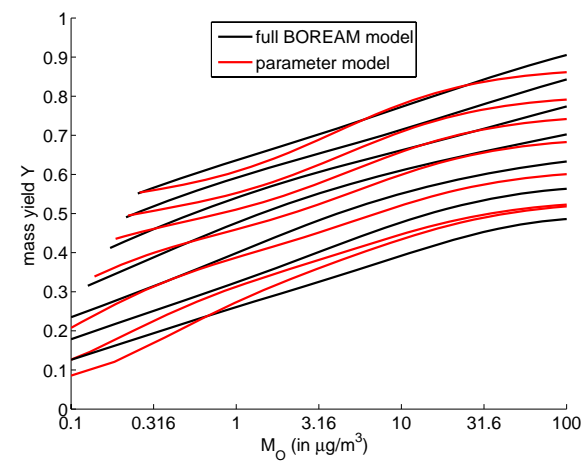

(a) low- $\mathrm{NO}_{\mathrm{x}} \mathrm{OH}$-oxidation

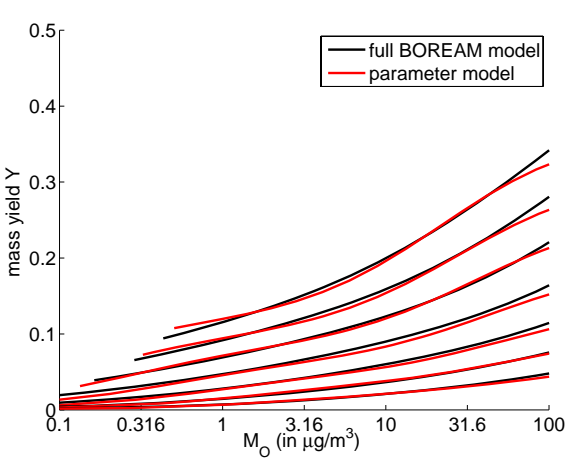

(b) high- $\mathrm{NO}_{\mathrm{x}} \mathrm{OH}$-oxidation

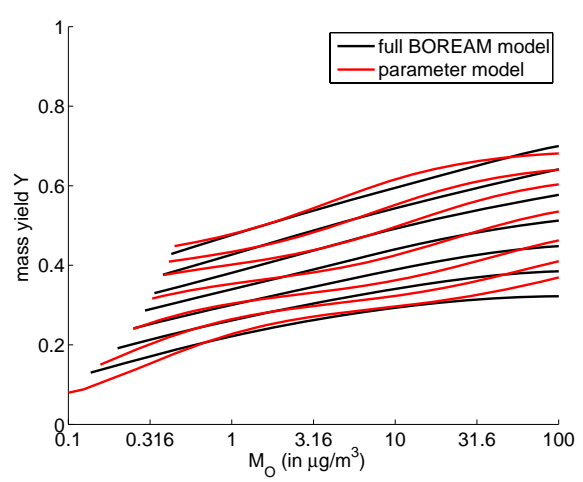

(c) low- $\mathrm{NO}_{\mathrm{x}} \mathrm{O}_{3}$-oxidation

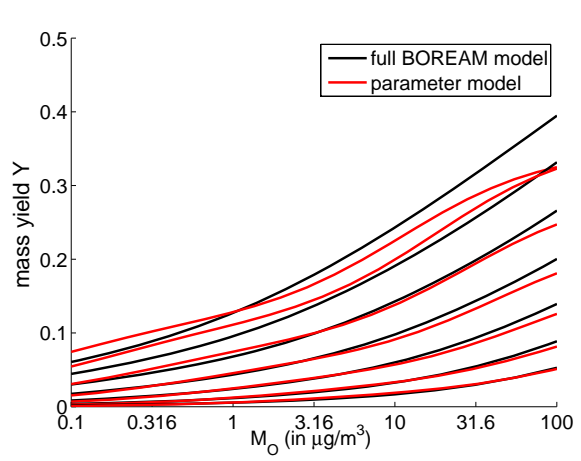

(d) high- $\mathrm{NO}_{\mathrm{x}} \mathrm{O}_{3}$-oxidation

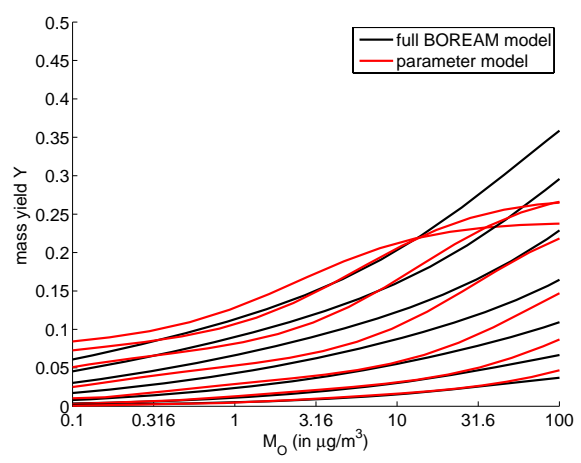

(e) high- $\mathrm{NO}_{\mathrm{x}} \mathrm{NO}_{3}$-oxidation

Fig. 5. Fitted (red) and full model (black) net equilibrium SOA mass yields as functions of the organic aerosol mass loading $M_{\mathrm{O}}$, for the low- $\mathrm{NO}_{\mathrm{x}} \mathrm{OH}$-oxidation scenario. The seven curves are obtained at temperatures ranging from 0 to $30^{\circ} \mathrm{C}$, by steps of $5^{\circ} \mathrm{C}$, the highest temperature corresponding to the lowest curve.

\subsection{Sensitivity of the parameterised yields to model assumptions}

Since photochemical conditions in the atmosphere might differ from the conditions assumed for the parameterisation, in this subsection we investigate the sensitivity of the parameterised yields to key parameters and assumptions.

\subsection{1 $\mathrm{NO}_{\mathrm{x}}$ dependence}

The $\mathrm{NO}_{\mathrm{x}}$ dependence of the parameterised model is based on full model runs at very high and very low $\mathrm{NO}_{\mathrm{x}}$ levels. As seen in Table 3, the parameterisation involves two peroxy radicals (PRAPOH1 and PRAPOH2) upon $\alpha$-pinene oxidation by $\mathrm{OH}$, and two peroxy radicals (PRAPO31 and PRAPO32) upon $\alpha$-pinene ozonolysis. A simpler parameterisation similar to the scheme used in Henze et al. (2008), in which only one peroxy radical was produced (i.e. when the branching ratios $\beta_{\mathrm{OH}}$ and $\beta_{\mathrm{O}_{3}}$ towards the second-generation peroxy radicals PRAPOH 2 and PRAPO32 are zero), has been tested, but was found to lead to significant SOA overestimates at intermediate $\mathrm{NO}_{\mathrm{x}}$ levels. This can partly be explained by the fact that the peroxy radicals reacting with $\mathrm{HO}_{2}$ in the parameter model would in that case immediately yield highly condens- able low- $\mathrm{NO}_{\mathrm{x}}$ products, which in the full model correspond to products formed only after several subsequent reactions of peroxy radicals with $\mathrm{HO}_{2}$, for example hydroxy dihydroperoxides. In the full model, however, a reaction with $\mathrm{HO}_{2}$ can be followed by a reaction with $\mathrm{NO}$ at intermediate $\mathrm{NO}_{\mathrm{x}}$, leading to the formation of a much more volatile product in the full BOREAM model.

The introduction of the second generation peroxy radicals PRAPOH2 and PRAPO32, produced with a fitted branching ratio $\beta_{i}(T)$ from the reactions of the first peroxy radicals with $\mathrm{HO}_{2}$, as seen in Table 3 , results in a redistribution between high and low- $\mathrm{NO}_{\mathrm{x}}$ products, and to an improved agreement between full and parameter model at intermediate $\mathrm{NO}_{\mathrm{x}}$ levels for both $\mathrm{OH}$ and ozone oxidation. It was not found necessary to introduce such a branching to a second peroxy radical for the reaction of the first generation peroxy radicals with NO. The temperature dependent fitted function for both $\beta_{\mathrm{OH}}$ and $\beta_{\mathrm{O}_{3}}$ is $4.286 \times 10^{-4} \cdot T^{2}-0.2181 \cdot T+27.53$ for the range 278 to $303 \mathrm{~K}$, while outside this range the function remains constant at the values it has at the edge of the fitting range. We have checked the agreement of full and parameter model at intermediate- $\mathrm{NO}_{\mathrm{x}}$ levels at different temperatures. The curves of the net mass yields $Y_{\text {net }}$ near SOA equilibrium, 


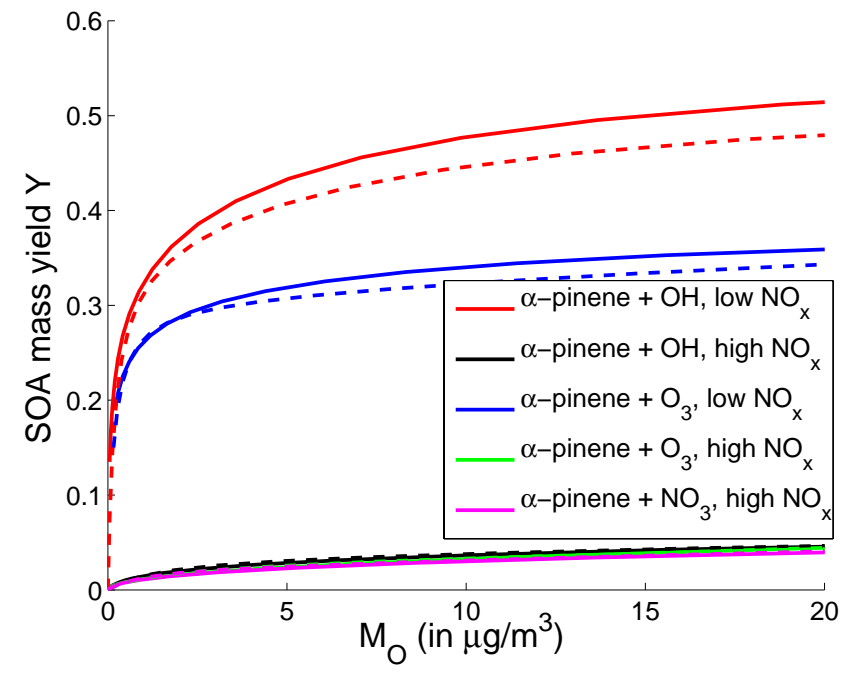

Fig. 6. Net SOA mass yields near SOA equilibrium in the full model (solid lines) and parameter model (dashed lines) at $298 \mathrm{~K}$ for the five $\alpha$-pinene oxidation scenarios, as functions of organic aerosol mass loading.

as defined in the previous Sect. 3.3, versus $M_{\mathrm{O}}$ can be seen in Fig. 7 and Figs. S12 to S16 in the Supplement.

\subsubsection{Importance of aerosol photolysis for SOA ageing}

Aerosol photolysis has only little impact for the simulation of the experiments described in Table 2, which lasted only a few hours. Aerosol photolysis has, however, a potentially major impact on SOA yields after prolonged ageing. In the full model simulations, described in Sect. 3.2, turning off aerosol photolysis leads to a near doubling of the SOA yields, in particular for the oxidation of $\alpha$-pinene by $\mathrm{OH}$ under low$\mathrm{NO}_{\mathrm{x}}$ conditions, with SOA mass yields reaching values of around $100 \%$ (see Fig. 8, blue curve).

This strong sensitivity of SOA yields to aerosol photolysis is caused by the fact that most condensable species reside predominantly in the aerosol phase after several days of ageing. When photolysis of the aerosol phase species is ignored, only the small fraction of these condensable species left in the gas phase can undergo further reactions (photolysis or oxidation by $\mathrm{OH}$ ). The more volatile species, residing mostly in the gas phase, are oxidised in part to low-volatility compounds, which can move towards the aerosol phase, where they are shielded from further oxidation. This process will over time lead to an accumulation of very condensable oxidation products in the SOA. Aerosol photolysis can partly revolatilise these condensable species, except those which do not contain any photolabile chromophore. Ignoring aerosol photolysis will therefore likely lead to unrealistically high SOA yields in models, although large uncertainties exist, regarding the rates of aerosol phase photolysis reactions, and the further chemistry of the photolysis products. Further experimental work is clearly desirable. The curve for the SOA

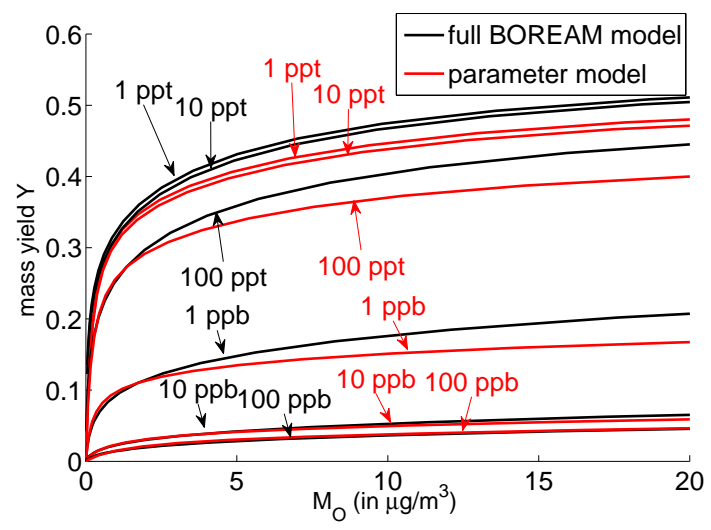

Fig. 7. Net SOA mass yields near SOA equilibrium calculated by the full (black) and parameterised (red) model at $\mathrm{NO}_{2}$ levels between $1 \mathrm{ppt}$ and $100 \mathrm{ppb}$, for $\mathrm{OH}$-oxidation of $\alpha$-pinene (at $298 \mathrm{~K}$ ).

loadings in a parameter model simulation in which particulate phase photolysis is ignored has been included (cyan curve). In this case there is also an increase in SOA concentration. However this increase in SOA is smaller than the one observed in the full model. The parameter model has not been designed in order to reproduce the case without aerosol photolysis, and it is therefore not expected to reproduce full model results in absence of aerosol photolysis. The results in Fig. 8 are referring to equilibrium net SOA yields, obtained after 12 days of the ageing scenario.

In a second sensitivity test, the solar zenith angle used in the calculation of photorates is increased from 20 to $45^{\circ}$ (but the prescribed oxidant levels are kept identical). This leads to an increase of SOA yields in the full model (solid green curve), e.g. from 0.48 to 0.59 at $M_{\mathrm{O}}=10 \mu \mathrm{g} \mathrm{m}^{-3}$. This increase is overestimated by the parameter model (at about 0.68 , solid magenta curve). This discrepancy is due to the fact that, as was mentioned in Sect. 3.2, the parameter model has not been explicitly fitted to match the full model for various radiation spectra.

The impact of other possible particulate phase chemistry reactions such as oligomerisation is difficult to estimate. We acknowledge that such reactions could be important for longterm ageing and this topic clearly requires further investigation.

\subsubsection{Influence of assumed $\mathrm{OH}$ and $\mathrm{HO}_{2}$ concentrations}

$\mathrm{OH}$ and $\mathrm{HO}_{2}$ play an important role in SOA formation, especially at low $\mathrm{NO}_{\mathrm{x}}$, since their concentrations determine the formation of hydroperoxides and other oxygenated species. As seen in Fig. 8, the SOA yields increase only slightly from 0.48 to 0.51 for $M_{\mathrm{O}}=10 \mu \mathrm{g} \mathrm{m}^{-3}$ in the full model (dotted black line), when the $\mathrm{OH}$ and $\mathrm{HO}_{2}$ concentrations are doubled. 


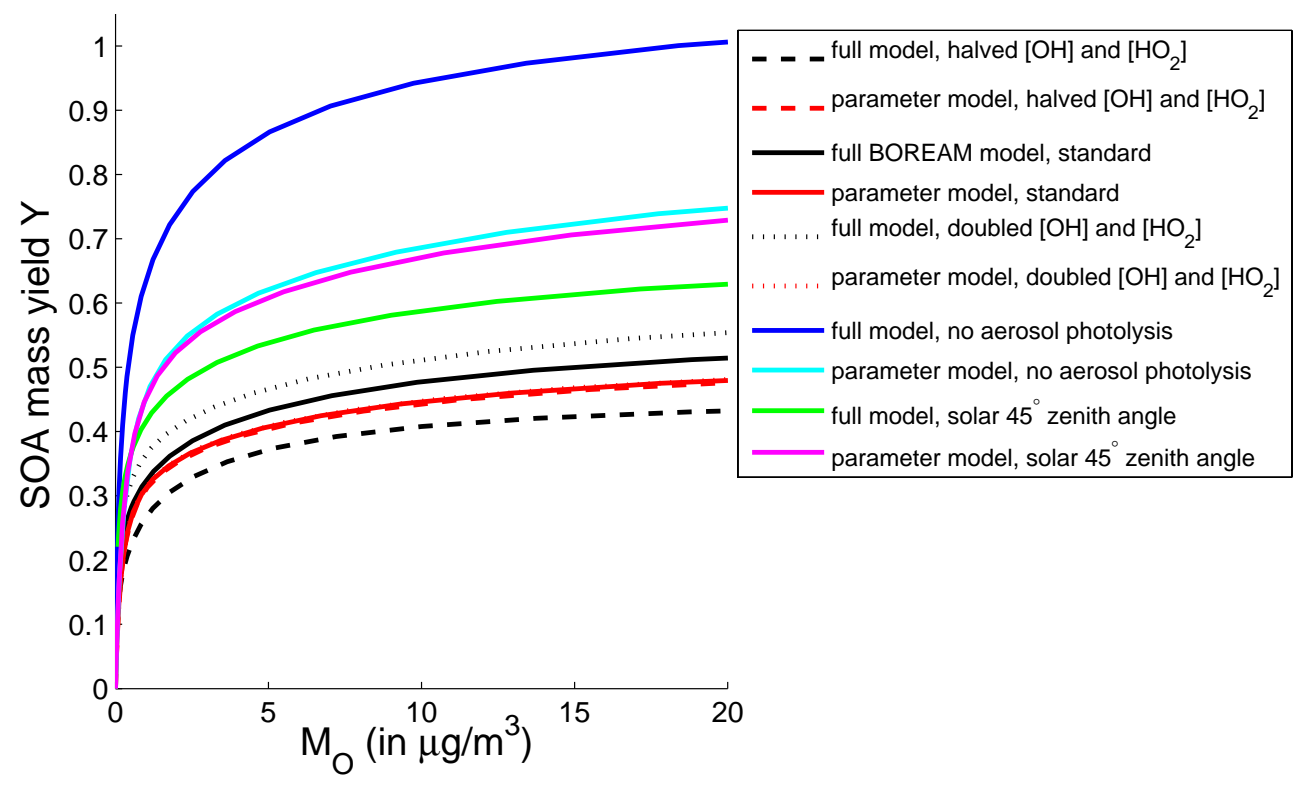

Fig. 8. Net SOA yields calculated for the $\mathrm{OH}$-oxidation of $\alpha$-pinene at low- $\mathrm{NO}_{\mathrm{x}}$ scenario, at $298 \mathrm{~K}$, for sensitivity tests with the full model and the parameter model for variations in $\mathrm{OH}$ and $\mathrm{HO}_{2}$ concentrations, solar zenith angle and absence of particulate phase photolysis. These equilibrium SOA yields are obtained after 12 days into the photo-chemical ageing scenario.

Halving the $\mathrm{OH}$ and/or $\mathrm{HO}_{2}$ levels leads to a comparatively larger change. E.g. at $M_{\mathrm{O}}=10 \mu \mathrm{g} \mathrm{m}^{-3}$, the SOA yield at low- $\mathrm{NO}_{\mathrm{x}}$ is reduced from 0.48 to 0.41 when both the $\mathrm{OH}$ and $\mathrm{HO}_{2}$ concentrations are halved in the full model (dashed black line). In contrast, the net SOA mass yields of the parameter model (in red) are not sensitive to these variations, as expected, since there is no direct impact of $\mathrm{OH}$ and $\mathrm{HO}_{2}$ concentrations on the properties of condensable products in the parameter model. In conclusion, the use of a fixed diurnal profile for $\mathrm{OH}$ and $\mathrm{HO}_{2}$ in the model calculations introduces an uncertainty in the parameterised SOA formation rate, estimated to be typically of the order of $10-15 \%$.

\subsubsection{Sensitivity to generic chemistry parameters in BOREAM}

Sensitivity tests were conducted to evaluate the impact of several key parameters related to $\mathrm{OH}$ reactions and photolysis of the generic species, similar to the ones shown in Fig. 2, but here applied to the long-term SOA ageing scenarios, as shown in Fig. 9. For the low- $\mathrm{NO}_{\mathrm{x}} \mathrm{OH}$-oxidation scenario a significant decrease in SOA is observed when $k_{\mathrm{LX}}$, the reaction rate for $\mathrm{OH}$ with the generic part of the generic species, is set to zero (see the blue curve). If by contrast $k_{\mathrm{LX}}$ would be twice or four times higher than the assumed standard value in BOREAM then only a moderate increase in SOA is found (green solid and dash-dotted curves). A test where the $\mathrm{j}$-value for the generic part $j_{\mathrm{LXALD}}$ is reduced to zero shows that this could lead to a significant increase in SOA (red), although a more realistic reduction of $j_{\text {LXALD }}$ by 50 percent leads to a more moderate increase (red dash-dotted line). Sensitivity to the assumed alkoxy radical branching between $\mathrm{H}$-shift isomerisation and decomposition is found to be moderate for the $\mathrm{OH}$ low- $\mathrm{NO}_{\mathrm{x}}$ scenario (magenta and cyan). By contrast, for the $\mathrm{OH}$ high- $\mathrm{NO}_{\mathrm{x}}$ scenario sensitivity to the alkoxy radical branching parameters for the generic species is found to be strong. In the unrealistic case where all generic alkoxy radicals would undergo $\mathrm{H}$-shift isomerisation, a very strong increase in simulated SOA concentration is found (cyan solid line). Setting the branching ratio to 50 percent $\mathrm{H}$-shift isomerisation still leads to more than a doubling of SOA yields. Therefore we can conclude that for high-NO ${ }_{\mathrm{x}}$ long term ageing scenarios, uncertainty on SOA concentrations simulated by the BOREAM model is considerable due to the uncertainty on parameters related to alkoxy radicals in the generic chemistry. Note that even in a fully explicit mechanism the uncertainty on the structure activity relationships for alkoxy radical reactions is often considerable (Vereecken and Peeters, 2010). Sensitivity of simulated SOA to the $k_{\mathrm{LX}}$ and $j_{\mathrm{LXALD}}$ is also significant for high- $\mathrm{NO}_{\mathrm{x}}$, although less pronounced than sensitivity to the alkoxy radical branching. Further attempts to constrain the generic parameters by experimental or theoretical means could improve the accuracy of simulated SOA concentrations for long-term ageing by BOREAM.

\subsubsection{Comparison of full and parameter model for simulations based on ambient conditions}

In order to test the ability of the parameter model to reproduce the full BOREAM model $\alpha$-pinene SOA loadings under ambient conditions, simulations are performed in which 


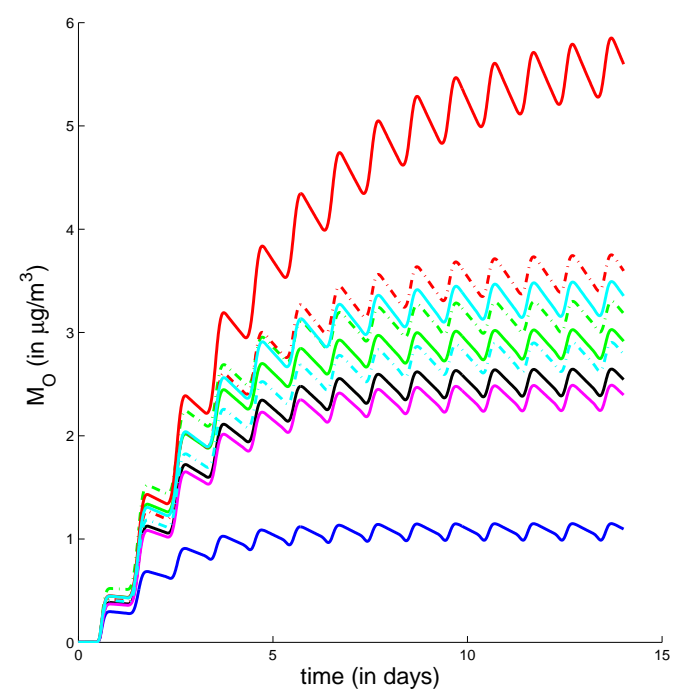

(a) low- $\mathrm{NO}_{x} \mathrm{OH}$-oxidation scenario

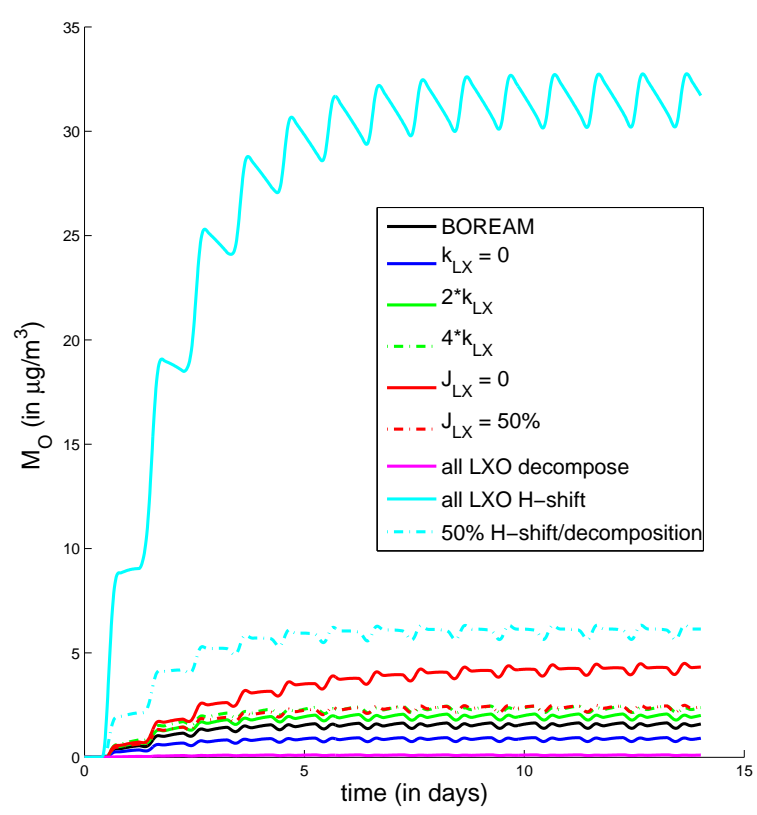

(b) high- $\mathrm{NO}_{x}$ OH-oxidation scenario

Fig. 9. Sensitivity tests for SOA yields to the assumed reaction constant with $\mathrm{OH}$ of the generic part of generic species classes, $k_{\mathrm{LX}}$, to the J-value $j_{\text {LXALD }}$ of this generic part and to the branching ratios of generic alkoxy radicals, similar to the tests shown in Fig. 2, for OH oxidation under (a) low (left panel) and (b) high- $\mathrm{NO}_{\mathrm{x}}$ conditions (right).

the previously investigated sensitivities (to mass loading, temperature, $\mathrm{NO}_{\mathrm{x}}$-regime, oxidant levels and applied radiation) are probed using more realistic atmospheric scenarios. The global chemistry transport model IMAGESv2 (e.g. Stavrakou et al., 2012) was used to obtain time series of temperature, $\alpha$-pinene emission rates and the concentrations of important atmospheric species over 5 months (from May until September) at 17 selected locations around the globe (see Table S11 in the Supplement for an overview). The IMAGESv2 output is averaged over the troposphere (weighted by the gas phase $\alpha$-pinene product concentrations) and applied in the box models. OA from other sources than the monoterpenes (primary organic aerosol and SOA from isoprene, aromatics, sesquiterpenes and small dicarbonyls) was also modelled in these IMAGESv2 simulations using parameterisations from the literature (Stavrakou et al., 2009, 2012). This additional OA also contributes to the total absorbing organic mass in our box model simulations. In the box model, monoterpene SOA concentrations are taken to be zero at the start of the month. Water uptake is ignored.

The level of agreement between full and parameter model differs for the different locations, depending on atmospheric conditions. An overall view of the parameter model skill is provided by Fig. 10, where the daily averaged values $M_{\mathrm{O}}$ due to $\alpha$-pinene in the parameter model $\left(\overline{M_{\mathrm{O}, \mathrm{p}, i}}\right)$ are represented against the corresponding values in the full model $\left(\overline{M_{\mathrm{O}, \mathrm{f}, i}}\right)$. We calculate an averaged relative difference factor per location using $\sum\left|\overline{M_{\mathrm{O}, \mathrm{p}, i}}-\overline{M_{\mathrm{O}, \mathrm{f}, i}}\right| / \sum \overline{M_{\mathrm{O}, \mathrm{f}, i}}$. Similarly we calculate an averaged bias factor using

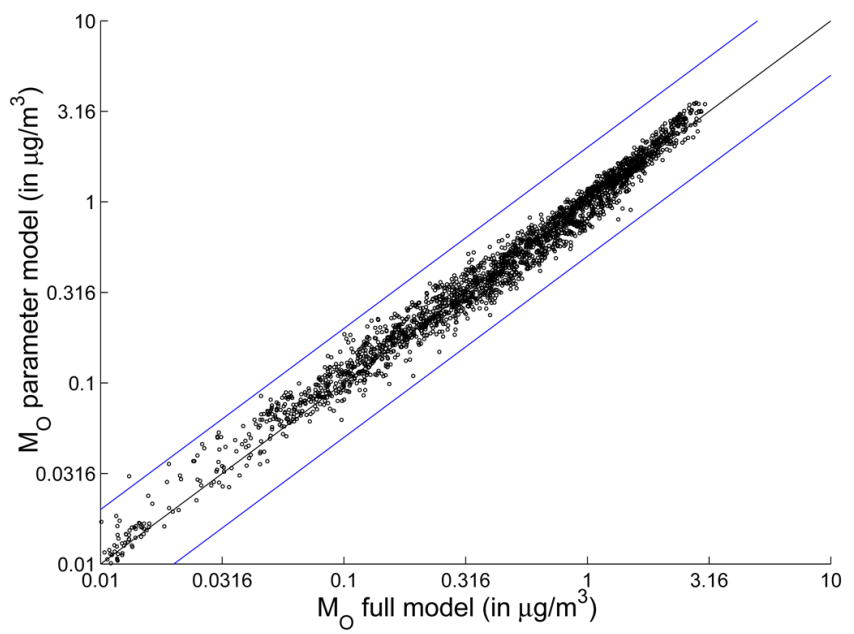

Fig. 10. Daily averaged $\alpha$-pinene $M_{\mathrm{O}}$ parameter model values versus full BOREAM model values for 17 locations during 5 months, using ambient data simulated with the global CTM IMAGESv2. The blue lines indicate the region of agreement to within a factor two.

$\sum\left(\overline{M_{\mathrm{O}, \mathrm{p}, i}}-\overline{M_{\mathrm{O}, \mathrm{f}, i}}\right) / \sum \overline{M_{\mathrm{O}, \mathrm{f}, i}}$. For most locations agreement is quite good, as can be seen in Figs. 10 and 11 and Table S11 and Fig. S17 in the Supplement. The largest deviations are found for Queensland, where there is on average an overestimation of about $25 \%$, and for Finland and the Pearl River Delta, where the parameter model SOA concentrations 


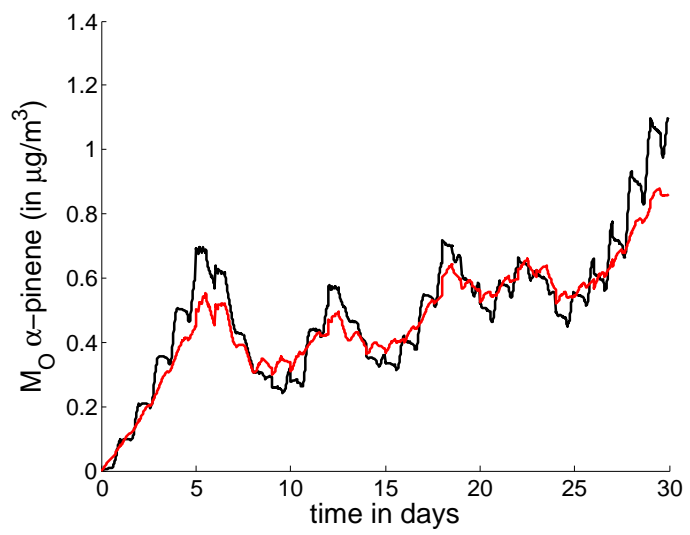

(a) South-East US

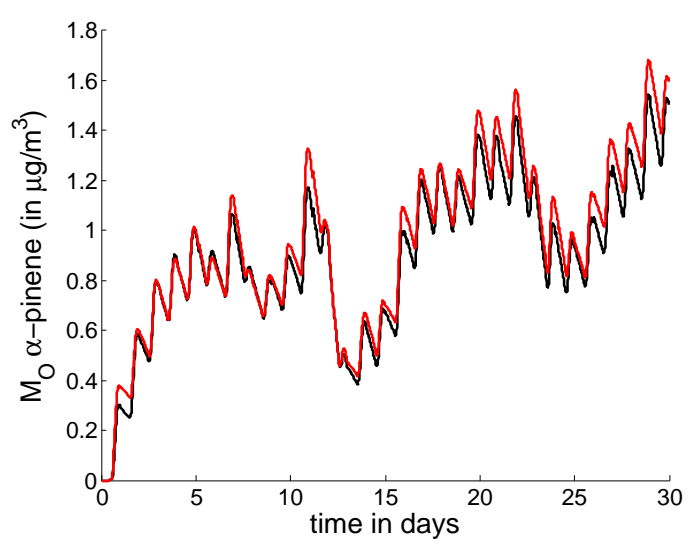

(c) Peru

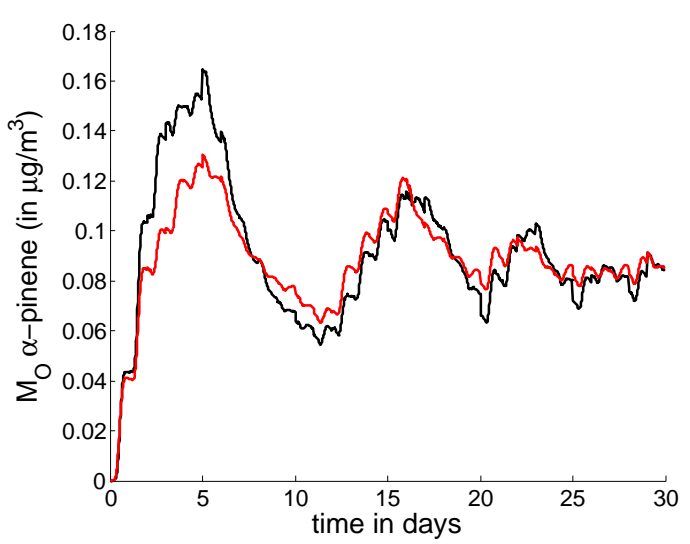

(b) Belgium

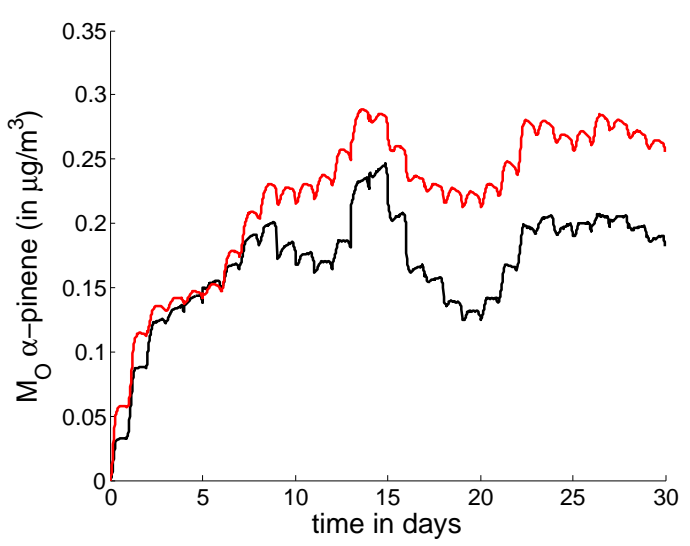

(d) Queensland

Fig. 11. Example of time evolution of $\alpha$-pinene SOA in the full BOREAM model (black) versus the parameter model (red) for simulations based on atmospheric conditions simulated with the CTM IMAGESv2, shown here for the month of July.

are on average about 20 percent too low. These deviations are probably partly caused by the fact that the fitting procedure was not always entirely successful in matching SOA formation at all times and for all photo-chemical condititions (see Sect. 3.3). A second cause of error is that the parameter fitting did not consider possible impacts of variations in atmospheric conditions, such as variable radiation or concentrations of oxidants (see Sects. 3.4.2 and 3.4.3). In most other locations, such as for example The United States, Belgium and Peru, agreement is better; on average over all locations the deviation is about $11 \%$, with only little bias. Given the large uncertainties associated to SOA model estimates, this level of agreement between parameter and full model seems satisfactory.

\subsection{Comparison with parameterised models based on experimental yields}

A non-exhaustive overview of parameterisations for SOA formation from $\alpha$-pinene based on smog chamber studies is given in Table 5. Figure 12 compares the SOA yield curves for these studies with the parameterisation obtained with
BOREAM. The reference temperature is taken to be $298 \mathrm{~K}$, to allow for proper comparison. For those experimental parameterisations which do not contain an explicit temperature dependence, we adjusted the partitioning equilibrium constants by use of Eq. (3), assuming a value for $\Delta H_{\text {vap }} / R$ of $5000 \mathrm{~K}$, although it should be noted that a large uncertainty exists for the enthalpy of vapourisation of SOA (Stanier et al., 2008). For the parameterisation of Hoffmann et al. (1997) this adjustment nearly doubles the SOA yield, but for most other parameterisations the difference is less important.

Figure 12 shows a very large variation between the different parameterisations based on experiments, stressing the large impact of experimental conditions on the SOA yields. Most experimental SOA yield curves fall between the high yields of the low- $\mathrm{NO}_{\mathrm{x}}$ BOREAM results and the low yields for the high- $\mathrm{NO}_{\mathrm{x}}$ scenario. Low-NO $\mathrm{NO}_{\mathrm{x}}$ BOREAM-based parameter model scenario yields are considerably higher than those for the experimental studies, partly due to the fact that in the BOREAM-based parameter model scenarios ageing has a larger impact. These model scenarios assume an average lifetime of 6 days for the gas and aerosol species, much 
Table 5. Parameterisations for $\alpha$-pinene SOA based on smog chamber experiments. VBS = Volatility Basis Set.

\begin{tabular}{|c|c|c|c|c|c|}
\hline Study & Type & Oxidant & $\mathrm{NO}_{\mathrm{x}}$ depend. & $T$ depend. & Radiation \\
\hline Odum et al. $(1996)^{\mathrm{a}}$ & 2-product & $\mathrm{OH}$ and $\mathrm{O}_{3}$ & no (intermediate $\mathrm{NO}_{\mathrm{x}}$ ) & no $( \pm 321 K)$ & solar \\
\hline Griffin et al. (1999) & 2-product & $\mathrm{O}_{3}{ }^{\mathrm{d}}$ & no $\left(\right.$ low $\left.\mathrm{NO}_{\mathrm{x}}\right)$ & no $(308 \mathrm{~K})$ & dark \\
\hline Cocker III et al. (2001) & 2-product & $\mathrm{O}_{3}{ }^{\mathrm{d}}$ & no $\left(\right.$ low $\mathrm{NO}_{\mathrm{x}}$ ) & no $(301 \mathrm{~K})$ & dark \\
\hline Presto et al. (2005a) & 2-product & $\mathrm{O}_{3} \mathrm{~d}$ & yes (low and high $\mathrm{NO}_{\mathrm{x}}$ ) & no $(295 \mathrm{~K})$ & with/without UV \\
\hline Saathoff et al. (2009) & 2-product & $\mathrm{O}_{3}{ }^{\mathrm{d}}$ & no $\left(\right.$ low $\left.\mathrm{NO}_{\mathrm{x}}\right)$ & yes & dark \\
\hline Pye et al. $(2010)^{\mathrm{b}}$ & VBS & $\mathrm{O}_{3}{ }^{\mathrm{d}}$ & yes (low and high $\mathrm{NO}_{\mathrm{x}}$ ) & no $(298 \mathrm{~K})$ & dark \\
\hline Farina et al. $(2010)^{\mathrm{c}}$ & VBS & $\mathrm{OH}$ and $\mathrm{O}_{3}$ & $\begin{array}{l}Y_{\text {highNO }}=\frac{1}{2} \cdot Y_{\text {low NO }_{x}} \\
\text { yes (low and high } \mathrm{NO}_{\mathrm{x}} \text { ) }\end{array}$ & no & blacklight \\
\hline
\end{tabular}

${ }^{a}$ based on Hoffmann et al. (1997), ${ }^{\text {b }}$ based on Shilling et al. (2008), ${ }^{\mathrm{c}}$ based on Hoffmann et al. (1997), Ng et al. (2006), Ng et al. (2007a),

$\mathrm{d}$ including an $\mathrm{OH}$-scavenger.

longer than the duration of the smog chamber experiments, which typically last several hours. Moreover, in most ozonolysis studies, $\mathrm{OH}$ scavengers were used, which limits the extent of further ageing which the primary products can undergo. In the low- $\mathrm{NO}_{\mathrm{x}}$ model scenario utilised for fitting the BOREAM-based parameter model, the continuous exposure of products to $\mathrm{OH}$ and $\mathrm{HO}_{2}$ is responsible for much of the increase in functionalisation (with for example additional hydroperoxide groups as a result) and decrease in volatility of the oxidation products. In shorter experiments, or in experiments without $\mathrm{OH}$, this process will be limited, and SOA yields remain lower.

By contrast, for the high- $\mathrm{NO}_{\mathrm{x}}$ parameterisation based on BOREAM, SOA yields are lower than in most parameterisations from other studies based on high- $\mathrm{NO}_{\mathrm{x}}$ photooxidation experiments. In the BOREAM simulations of photooxidation at high- $\mathrm{NO}_{\mathrm{x}}$, the reaction with $\mathrm{NO}$ yields mostly alkoxy radicals, and some nitrates or peroxy acyl nitrates (PANs) as side products. The alkoxy radicals can in some cases decompose, which leads to smaller carbon chains or to a loss of oxygenated functional groups, increasing volatility. This explains the large difference found between high and low- $\mathrm{NO}_{\mathrm{x}}$ yields, and also why ageing over a long time period of two weeks under high- $\mathrm{NO}_{\mathrm{x}}$ conditions might lead to lower SOA yields than seen in high- $\mathrm{NO}_{\mathrm{x}}$ photooxidation experiments of shorter duration (several hours). As an illustration, the high$\mathrm{NO}_{\mathrm{x}}$ experimental yield of $\mathrm{Ng}$ et al. (2007a) experiment 4 is shown in Fig. 12. This yield is higher than in the BOREAM scenario for photooxidation at high- $\mathrm{NO}_{\mathrm{x}}$. It should be noted that in the simulation of this experiment, the full BOREAM model calculated SOA yields comparable to the experimental SOA yields (see Figs. 1, 2b and S6 in the Supplement). One exception is the high- $\mathrm{NO}_{\mathrm{x}}$ case of Presto et al. (2005a) in which even lower yields were found. This last experiment was a dark ozonolysis experiment with an $\mathrm{OH}$ scavenger, resulting in only first generation products, which are generally less condensable than more aged products.

Experimental SOA parameterisations for $\alpha$-pinene have been used in several global modelling studies, where they

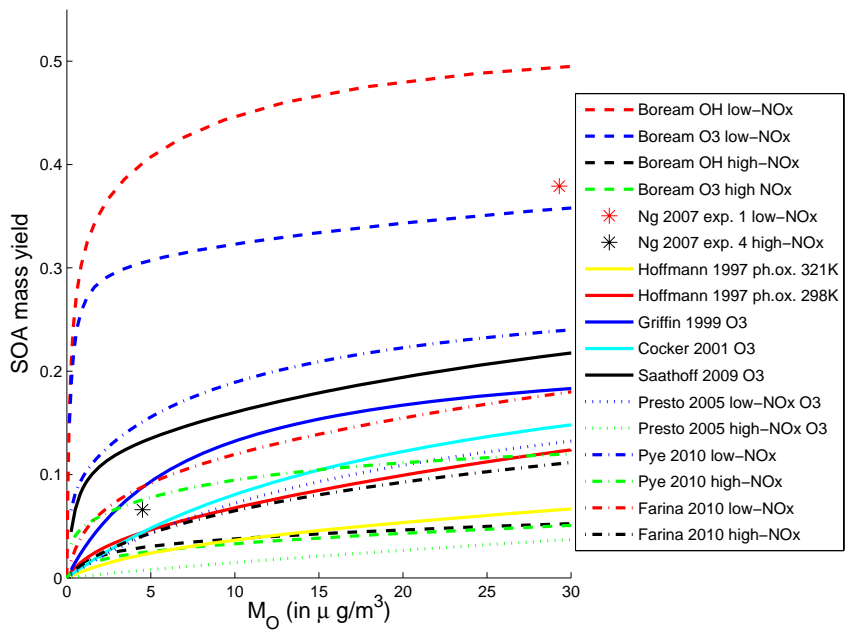

Fig. 12. Comparison of previously derived SOA mass yield curves from other studies, based on smog chamber experiments, with parameterisations based on the BOREAM model (four scenarios, dashed lines). Also shown are the measured experimental yields of experiments 1 and 4 in $\mathrm{Ng}$ et al. (2007a).

are generally used to represent SOA from the monoterpene family. Pye et al. (2010) used a $\mathrm{NO}_{\mathrm{x}}$-dependent parameterisation, for which the low- $\mathrm{NO}_{\mathrm{x}}$ yield is based on the study of Shilling et al. (2008), which consisted of dark ozonolysis experiments with addition of an $\mathrm{OH}$ scavenger. The $\mathrm{ab}-$ sence of $\mathrm{OH}$ can partly explain their lower yield compared to BOREAM. Farina et al. (2010) used a $\mathrm{NO}_{\mathrm{x}}$-dependent parameterisation of a 4-product volatility basis set, based on the studies of Hoffmann et al. (1997), Ng et al. (2006) and $\mathrm{Ng}$ et al. (2007a). Their high-NO $\mathrm{N}_{\mathrm{x}}$ yields lie somewhat lower than the high- $\mathrm{NO}_{\mathrm{x}}$ experimental yields of $\mathrm{Ng}$ et al. (2007a) and the temperature-adjusted parameterisation of Hoffmann et al. (1997). Their low-NO $\mathrm{N}_{\mathrm{x}}$ curve is considerably lower than the low- $\mathrm{NO}_{\mathrm{x}}$ experimental yield of $\mathrm{Ng}$ et al. (2007a), and the low- $\mathrm{NO}_{\mathrm{x}}$ BOREAM yield curve. 


\subsection{Treatment of water uptake and water activity}

In Compernolle et al. (2009) the UNIFAC method for activity coefficient calculation, as implemented by Hansen et al. (1991), was extended to include missing atmospherically relevant functional groups, such as the hydroperoxide, peroxyacid, nitrate and peroxy acyl nitrate groups. This method was applied in all BOREAM simulations presented in this study. However, water uptake was not considered in these simulations, although it is expected to increase the total number of molecules in the absorbing phase, and therefore also the partitioning to the particulate phase of organic semi-volatile compounds.

These effects are included in our parameterisation through the introduction of an activity coefficient for water, $\gamma_{\mathrm{H}_{2} \mathrm{O}}$, and a pseudo-activity coefficient for the organics in SOA, $\gamma_{\text {Org }}$. Both parameters are estimated from BOREAM simulations including water uptake, conducted at a temperature of $288 \mathrm{~K}$ and at relative humidity values ranging between 0 and $99.9 \%$.

As a simplification, the SOA is treated as a binary mixture of water and one organic pseudo-compound, which represents the entire organic fraction of the SOA. The overall pseudo-activity coefficient $\gamma_{\mathrm{Org}}$ accounts for the nonideality effects which the added water exerts on the organic compounds, whereas the non-ideality effects among organic compounds are implicitly accounted for in the parameterisation without water uptake.

Figure 13 shows the resulting dependence of the water activity coefficient on relative humidity. At relatively low relative humidity (typically below $60 \%$ ), the water activity coefficient is lower than 1 , leading to an increased water concentration in SOA, compared to the ideal case, in which the relative molecular water concentration would be equal to the relative humidity. $\gamma_{\mathrm{H}_{2} \mathrm{O}}$ reaches a maximum of 1.08 for the low- $\mathrm{NO}_{\mathrm{x}}$ scenario at $92 \% \mathrm{RH}$. At higher $\mathrm{RH}$ values, $\gamma_{\mathrm{H}_{2} \mathrm{O}}$ decreases towards a value of 1 at $100 \%$ RH. This is expected, as the organic fraction becomes very small, causing nonideality effects of the organic fraction to become negligible.

Two methods are used to derive the pseudo-activity coefficient $\gamma_{\text {Org }}$ for the organic fraction. In the first method, $\gamma_{\text {org }}$ is obtained from the modelled activity coefficient and molecular fraction of water in SOA. Indeed, for a binary mixture, when the molar fraction and activity coefficient for one component are known, the Gibbs-Duhem relationship at constant temperature and pressure (Poling et al., 2001)

$x_{1}\left(\frac{\partial \ln \gamma_{1}}{\partial x_{1}}\right)_{T, P}=x_{2}\left(\frac{\partial \ln \gamma_{2}}{\partial x_{2}}\right)_{T, P}$

might be used to derive the activity coefficient of the other component through an integration. At $x_{1}=0$, the activity coefficient of the second component is 1 , and $\ln \gamma_{2}=0$. We can then integrate Eq. (5) from $x_{1}=0$ to any $x_{1}$ (Olander, 2007):

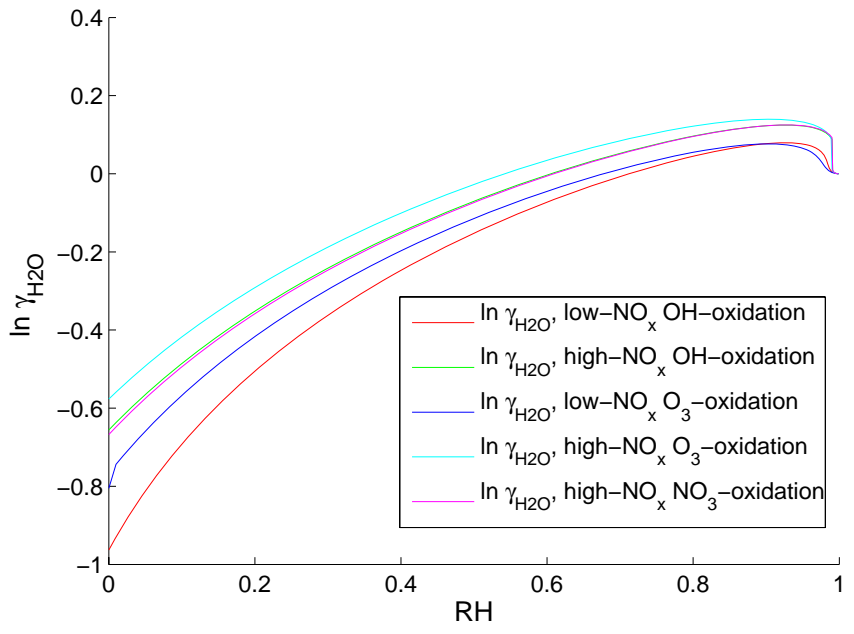

Fig. 13. The activity coefficient of water in function of RH, for the five oxidation scenarios (at $288 \mathrm{~K}$ ).

$\int_{\ln \gamma_{2}\left(x_{1}=0\right)}^{\ln \gamma_{2}\left(x_{1}\right)} \mathrm{d} \ln \gamma_{2}=\ln \gamma_{2}=-\int_{\ln \gamma_{1}\left(x_{1}=0\right)}^{\ln \gamma_{1}\left(x_{1}\right)} \frac{x_{1}}{1-x_{1}} \mathrm{~d} \ln \gamma_{1}$

Taking water and the organic fraction to be component 1 and $2, \gamma_{2}=\gamma_{\text {Org }}$ can be obtained by the numerical evaluation of the integral on the right-hand side of Eq. (6), with $\gamma_{1}$ and $x_{1}$ provided by BOREAM model simulations.

Comparing simulated $M_{\mathrm{O}}$ values including water for the parameter model and the full model (Fig. 15), a good agreement is found for the low- $\mathrm{NO}_{\mathrm{x}} \mathrm{OH}$-oxidation. For the other oxidation scenarios, however, the use of the Gibbs-Duhem

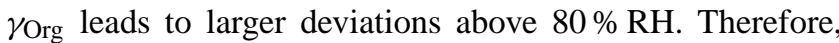
for high- $\mathrm{NO}_{\mathrm{x}}$ conditions a direct optimisation of $\gamma_{\mathrm{Org}}$ was performed instead, at $160 \mathrm{RH}$ values between 0 and $100 \%$, which minimises the difference in $M_{\mathrm{O}}$ between full and parameterised model (shown in Fig. 14). As can be seen in Fig. 15, these values lead to an excellent agreement of the SOA yields for the high- $\mathrm{NO}_{\mathrm{x}}$ scenario. Tabulated values for $\gamma_{\mathrm{H}_{2} \mathrm{O}}$ and $\gamma_{\mathrm{Org}}$ for the oxidation scenarios can be found in Tables S12 and S13 of the Supplement. Sensitivity tests in which the activity coefficients are given constant values (1 or 1.1 for $\gamma_{\mathrm{H}_{2} \mathrm{O}}$, and 1 for the organic species) show that at high RH the use of these constant values for the $\gamma$ can lead to important discrepancies (Fig. 15).

Extrapolation to intermediate $\mathrm{NO}_{\mathrm{x}}$ levels of the above parameterisation for water uptake and water activity can be performed as follows. The values of $\gamma_{\mathrm{Org}, i}$ for each oxidation scenario are assigned to the corresponding condensable products. $\gamma_{\mathrm{H}_{2} \mathrm{O}}$ is extrapolated based on the mass fraction of products corresponding to oxidation scenario $i$ in the SOA, $r_{i}$, using $\gamma_{\mathrm{H}_{2} \mathrm{O}}=\prod\left(\gamma_{\mathrm{H}_{2} \mathrm{O}, i}\right)^{r_{i}}$. We have performed simulations at intermediate $\mathrm{NO}_{\mathrm{x}}\left(100 \mathrm{ppt}\right.$ and $\left.1 \mathrm{ppb} \mathrm{NO} \mathrm{NO}_{2}\right)$, showing that the agreement between full and parameter model is good. 


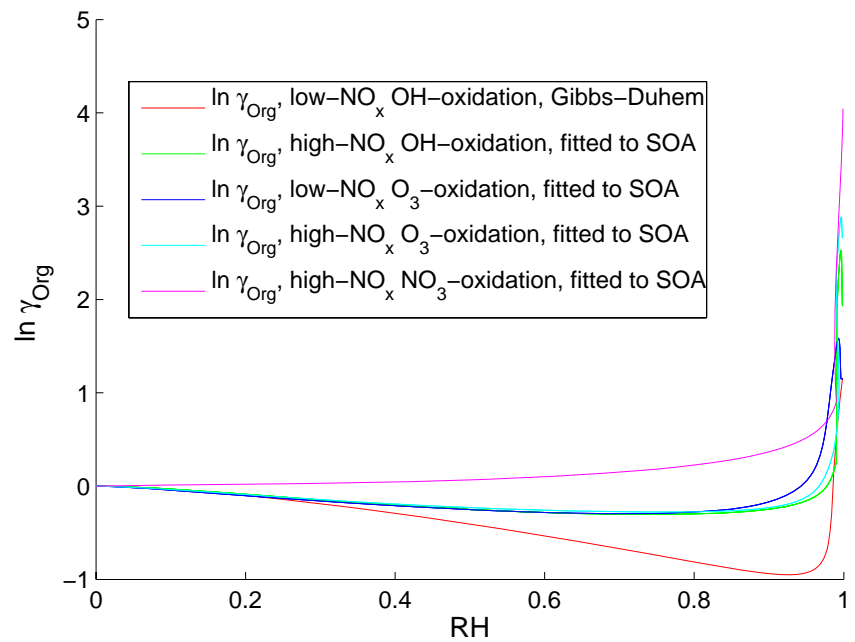

Fig. 14. The pseudo-activity coefficient $\gamma_{\text {Org }}$, which accounts for the non-ideality effects of water on the organic fraction (at $288 \mathrm{~K}$ ). For low- $\mathrm{NO}_{\mathrm{x}} \mathrm{OH}$-oxidation it is derived based on the Gibbs-Duhem equation (red curve). For the other scenarios, the use of this $\gamma_{\mathrm{Org}}$ based on Gibbs-Duhem does not always lead to a satisfactory agreement between full BOREAM SOA yields and the parameterisation. Therefore $\gamma_{\text {Org }}$ values derived by a direct fitting in order to optimise $M_{\mathrm{O}}$ agreement between full BOREAM and parameter model are used (other curves).

\section{Conclusions}

The detailed model BOREAM is used to simulate the formation of SOA accompanying $\alpha$-pinene oxidation under nearatmospheric conditions, including continued photochemical ageing.

The chemistry of further generation oxidation products is represented by a generic chemistry scheme in the full model, which is described in detail. Photolysis of species in the aerosol phase is included, in analogy with gas phase photolysis. Evaluation against a large number of photooxidation smog chamber experiments shows that most experimental SOA mass yields can be reproduced to within a factor 2. Uncertainties in the generic chemistry were found not to have a large impact on SOA for low- $\mathrm{NO}_{\mathrm{x}}$ experiments. At high $\mathrm{NO}_{\mathrm{x}}$, the branching ratios towards decomposition or H-shift isomerisation adopted for alkoxy radicals are found to have a possibly large influence on SOA.

BOREAM is used to design and adjust an SOA parameterisation for use in large-scale atmospheric models. The oxidation of $\alpha$-pinene by $\mathrm{OH}$, ozone and $\mathrm{NO}_{3}$ are modelled separately. Simulations are performed with BOREAM for lowand high- $\mathrm{NO}_{\mathrm{x}}$ conditions, using a prescribed diurnal cycle for radiation, oxidants and $\alpha$-pinene, while deposition of gas phase and particulate compounds is considered. The equilibrium SOA mass concentrations, reached typically after about 12 days, are used to constrain the parameters (temperaturedependent mass stoichiometric coefficients and partitioning

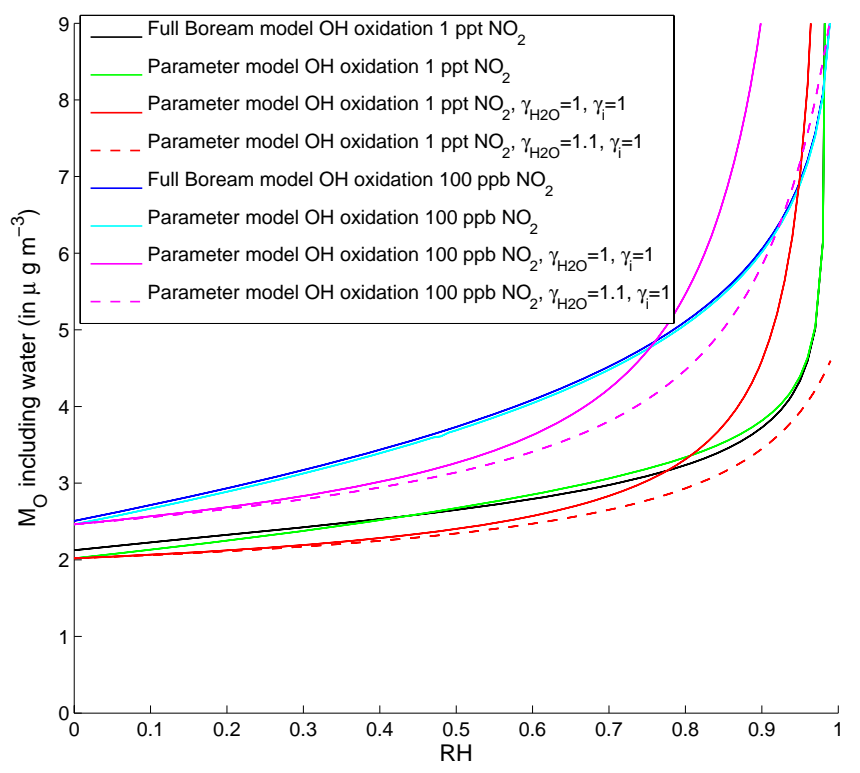

Fig. 15. The impact of relative humidity $(\mathrm{RH})$ on total absorbing mass $M_{\mathrm{O}}$ (including water), for the full model in the case of $\mathrm{OH}$ oxidation at low- $\mathrm{NO}_{\mathrm{x}}$ (black) and high- $\mathrm{NO}_{\mathrm{x}}$ (blue), at $288 \mathrm{~K}$. Note that the applied $\alpha$-pinene concentration was higher in the case of the high- $\mathrm{NO}_{\mathrm{x}}$ simulation shown here. The parameter model results are given in green for low $\mathrm{NO}_{\mathrm{x}}$ and cyan for high $\mathrm{NO}_{\mathrm{x}}$. Two sensitivity tests illustrate the model discrepancy resulting from the use of constant values for the activity coefficients in the parameter model.

constants) of 2 condensable products separately per oxidation scenario. In order to take into account the revolatilisation of condensable products due to photochemical processes, and to ensure sufficient agreement with the full model both during SOA build-up and when SOA has reached an equilibrium concentration, a pseudo-photolysis reaction is applied to the condensable products in the parameter model. The SOA parameterisation is shown to reproduce the SOA formation of the full BOREAM model reasonably well in the majority of cases at all $\mathrm{NO}_{\mathrm{x}}$ levels. At the highest temperatures and low SOA concentrations, the parameterisation is not always successful at reproducing the full model yields over the whole time range, but agreement is found to be sufficient near SOA equilibrium. A decrease of SOA mass yields is found for increasing $\mathrm{NO}_{\mathrm{x}}$ concentrations in the full model, which is generally well reproduced by the parameter model.

The SOA mass yields are shown to be relatively insensitive to variations of the concentrations of $\mathrm{OH}$ and $\mathrm{HO}_{2}$ adopted in the simulations. Increasing radiation intensity reduces SOA mass yields considerably, however (at similar oxidant levels). The photolysis of aerosol phase species has a large impact on the SOA mass yields in atmospheric conditions, since it is found to reduce SOA yields by a factor of about 2 after several days of ageing in the low- $\mathrm{NO}_{\mathrm{x}} \mathrm{OH}$-initiated oxidation scenario. Particulate phase photolysis is therefore a large factor of uncertainty which warrants further experimental studies. 
The low- $\mathrm{NO}_{\mathrm{x}}$ SOA mass yields in our model are found to be considerably higher (up to $50 \%$ mass yield for low- $\mathrm{NO}_{\mathrm{x}}$ $\mathrm{OH}$-oxidation) than in previously published SOA parameterisations based on smog chamber experiments. This is largely due to the fact that these smog chamber experiments were not conducted at the very low $\mathrm{NO}_{\mathrm{x}}$ concentrations (1 ppt) used in our model, and generally did not allow for much photochemical ageing, in contrast with the simulations performed here. The simulated high- $\mathrm{NO}_{\mathrm{x}}$ SOA yields, on the other hand, are found to be lower than in most experimental parameterisations.

Box model simulations under ambient conditions, as generated by a global chemistry-transport model, were conducted with the full and parameter model. Agreement overall between parameter and full model is found to be about around $10 \%$, with only a small minority of cases where deviations exceed $20 \%$, which is a satisfactory result given other larger uncertainties in connection with SOA models.

The parameterisation of water uptake involves an $\mathrm{RH}$ dependent activity coefficient for water, $\gamma_{\mathrm{H}_{2} \mathrm{O}}$, and an overall pseudo-activity coefficient $\gamma_{\mathrm{Org}}$, which accounts for the nonideality effects which the added water exerts on the organic compounds. Use of these adjusted activity coefficients in the parameterised model leads to a good agreement with the full model for all relative humidities, for both low, intermediate and high- $\mathrm{NO}_{\mathrm{x}}$ simulations.

The parameterisation for secondary organic aerosol from $\alpha$-pinene obtained in this work accounts for the influence of temperature, $\mathrm{NO}_{\mathrm{x}}$-regime, the impact of long-term photochemical ageing and water uptake, which was generally not the case for parameter models based on experiments, usually due to lack of sufficient data. It can therefore be used to estimate the impact of these factors in regional or global models, although it should be acknowledged that large uncertainties remain in the full BOREAM model, e.g. with respect to the photolysis of SOA and the further generation chemistry. Further model validation against long-term ageing experiments under various $\mathrm{NO}_{\mathrm{x}}$ conditions is desirable, as would be model intercomparison with other new SOA models (for example Valorso et al., 2011; Utembe et al., 2009; Xia et al., 2011, or other studies making use of the VBS approach). For wider application in SOA modelling it would also be necessary to extend this approach to other SOA precursors, and address the interaction with other types of aerosol components which might be present, such as primary organic aerosol or inorganic components.

\section{Supplementary material related to this article is available online at: http://www.atmos-chem-phys.net/12/ 5343/2012/acp-12-5343-2012-supplement.pdf.}

Acknowledgements. This research has been made possible through funding to the IBOOT (SD/AT/03) and BIOSOA (SD/CS/05A) projects, which are part of the programme "Science for a Sustainable Development" (SSD) of the Belgian Science Policy Office (BELSPO), and through the Action-1 research grant MO/35/027 of BELSPO.

Edited by: F. Keutsch

\section{References}

Capouet, M. and Müller, J.-F.: A group contribution method for estimating the vapour pressures of $\alpha$-pinene oxidation products, Atmos. Chem. Phys., 6, 1455-1467, doi:10.5194/acp-6-1455-2006, 2006.

Capouet, M., Peeters, J., Nozière, B., and Müller, J.-F.: $\alpha$-pinene oxidation by $\mathrm{OH}$ : simulations of laboratory experiments, Atmos. Chem. Phys., 4, 2285-2311, doi:10.5194/acp-4-2285-2004, 2004.

Capouet, M., Müller, J.-F., Ceulemans, K., Compernolle, S., Vereecken, L., and Peeters, J.: Modeling aerosol formation in $\alpha$-pinene photo-oxidation experiments, J. Geophys. Res., 113, D02308, doi:10.1029/2007JD008995, 2008.

Carlton, A. G., Bhave, P. V., Napelenok, S. L., Edney, E. O., Sarwar, G., Pinder, R. W., Pouliot, G. A., and Houyoux, M.: Model representation of secondary organic aerosol in CMAQv4.7, Environ. Sci. Technol., 44, 8553-8560, 2010.

Carter, W. P. L.: Documentation of the SAPRC-99 chemical mechanism for VOC reactivity assessment, final report to California Air Resources Board, contracts 92-329 and 95-308, Tech. rep., Air Pollut. Res. Cent. for Environ. Res. and Technol., Univ. of California, Riverside, California, http://www.cert.ucr. edu/ $\sim$ carter/reactdat.htm, 2000

Ceulemans, K., Compernolle, S., Peeters, J., and Müller, J.-F.: Evaluation of a detailed model of secondary organic aerosol formation from $\alpha$-pinene against dark ozonolysis experiments, Atmos. Environ., 44, 5434-5442, doi:10.5194/acp-9-1325-2009, 2010.

Chung, S. H. and Seinfeld, J. H.: Global distribution and climate forcing of carbonaceous aerosols, J. Geophys. Res., 107, 4407 , doi:10.1029/2001JD001397, 2002.

Cocker III, D. R., Clegg, S. L., Flagan, R. C., and Seinfeld, J. H.: The effect of water on gas-particle partitioning of secondary organic aerosol. Part I: $\alpha$-pinene/ozone system, Atmos. Environ., 35, 6049-6072, 2001.

Compernolle, S., Ceulemans, K., and Müller, J.-F.: Influence of non-ideality on condensation to aerosol, Atmos. Chem. Phys., 9, 1325-1337, doi:10.5194/acp-9-1325-2009, 2009.

Docherty, K. S. and Ziemann, P. J.: Effects of stabilized Criegee intermediate and $\mathrm{OH}$ radical scavengers on aerosol formation from reactions of $\beta$-pinene with $\mathrm{O}_{3}$, Aerosol Sci. Tech., 37, 877-891, 2003.

Engelhart, G. J., Hildebrandt, L., Kostenidou, E., Mihalopoulos, N., Donahue, N. M., and Pandis, S. N.: Water content of aged aerosol, Atmos. Chem. Phys., 11, 911-920, doi:10.5194/acp-11911-2011, 2011

Farina, S. C., Adams, P. J., and Pandis, S. N.: Modeling global secondary organic aerosol formation and processing with the volatility basis set: Implications for anthropogenic 
secondary organic aerosol, J. Geophys. Res., 115, D09202, doi:10.1029/2009JD013046, 2010.

Fredenslund, A., Jones, R. L., and Prausnitz, J. M.: Groupcontribution estimation of activity coefficients in nonideal liquid mixtures, AIChE J., 21, 1086-1099, 1975.

Griffin, R. J., Flagan, R. C., and Seinfeld, J. H.: Organic aerosol formation from the oxidation of biogenic hydrocarbons, J. Geophys. Res., 104, 3555-3567, doi:10.1029/1998JD100049, 1999.

Hallquist, M., Wenger, J. C., Baltensperger, U., Rudich, Y., Simpson, D., Claeys, M., Dommen, J., Donahue, N. M., George, C., Goldstein, A. H., Hamilton, J. F., Herrmann, H., Hoffmann, T., Iinuma, Y., Jang, M., Jenkin, M. E., Jimenez, J. L., KiendlerScharr, A., Maenhaut, W., McFiggans, G., Mentel, T. F., Monod, A., Prévôt, A. S. H., Seinfeld, J. H., Surratt, J. D., Szmigielski, R., and Wildt, J.: The formation, properties and impact of secondary organic aerosol: current and emerging issues, Atmos. Chem. Phys., 9, 5155-5236, doi:10.5194/acp-9-5155-2009, 2009

Hansen, H. K., Rasmussen, P., Fredenslund, A., Schiller, M., and Gmehling, J.: Vapor-liquid equilibria By UNIFAC group contribution. 5. Revision and extension, Ind. Eng. Chem. Res., 30, 2352-2355, doi:10.5194/acp-8-2405-2008, 1991.

Henze, D. K. and Seinfeld, J. H.: Global secondary organic aerosol from isoprene oxidation, Geophys. Res. Lett., 33, L09812, doi:10.1029/2006GL025976, 2006.

Henze, D. K., Seinfeld, J. H., Ng, N. L., Kroll, J. H., Fu, T.-M., Jacob, D. J., and Heald, C. L.: Global modeling of secondary organic aerosol formation from aromatic hydrocarbons: highvs. low-yield pathways, Atmos. Chem. Phys., 8, 2405-2420, doi:10.5194/acp-8-2405-2008, 2008.

Hildebrandt, L., Kostenidou, E., Mihalopoulos, N., Worsnop, D. R., Donahue, N. M., and Pandis, S. N.: Formation of highly oxygenated organic aerosol in the atmosphere: Insights from the Finokalia Aerosol Measurement Experiments, Geophys. Res. Lett., 37, L23801, doi:10.1029/2010GL045193, 2010.

Hoffmann, T., Odum, J. R., Bowman, F., Collins, D., Klockow, D., Flagan, R. C., and Seinfeld, J. H.: Formation of organic aerosols from the oxidation of biogenic hydrocarbons, J. Atmos. Chem., 26, 189-222, 1997.

Hofzumahaus, A., Rohrer, F., Lu, K., Bohn, B., Brauers, T., Chang, C.-C., Fuchs, H., Holland, F., Kita, K., Kondo, Y., Li, X., Lou, S., Shao, M., Zeng, L., Wahner, A., and Zhang, Y.: Amplified trace gas removal in the troposphere, Science, 324, 1702-1704, doi:10.1126/science.1164566, 2009.

Hoyle, C., Boy, M., Donahue, N. M., Fry, J. L., Glasius, M., Guenther, A., Hallar, A. G., Huff Hartz, K., Petters, M. D., Petäjä, T., Rosenoern, T., and Sullivan, A. P.: A review of the anthropogenic influence on biogenic secondary organic aerosol, Atmos. Chem. Phys., 11, 321-343, doi:10.5194/acp-11-321-2011, 2011.

Jenkin, M.: Modelling the formation and composition of secondary organic aerosol from $\alpha$ - and $\beta$-pinene ozonolysis using MCM v3, Atmos. Chem. Phys., 4, 1741-1757, doi:10.5194/acp-3-1812003, 2004.

Jimenez, J. L., Canagaratna, M. R., Donahue, N. M., Prevot, A. S. H., Zhang, Q., Kroll, J. H., DeCarlo, P. F., Allan, J. D., Coe, H., Ng, N. L., Aiken, A. C., Docherty, K. S., Ulbrich, I. M., Grieshop, A. P., Robinson, A. L., Duplissy, J., Smith, J. D., Wilson, K., Lanz, V. A., Hueglin, C., Sun, Y. L., Tian, J., Laaksonen, A., Raatikainen, T., Rautiainen, J., Vaattovaara, P., Ehn, M., Kul- mala, M., Tomlinson, J. M., Collins, D. R., Cubinson, M. J., Dunlea, E. J., Huffman, J. A., Onasch, T. B., Alfarra, M. R., Williams, P. I., Bower, K., Kondo, Y., Schneider, J., Drewnick, F., Borrmann, S., Weimer, S., Demerjian, K., Salcedo, D., Cottrell, L. Griffin, R. Takami, A., Miyoshi, T., Hatakeyama, S., Shimono, A., Sun, J. Y., Zhang, Y. M., Dzepina, K., Kimmel, J. R., Sueper, D., Jayne, J. T., Herndon, S. C., Trimborn, A. M., Williams, L. R., Wood, E. C., Middlebrook, A. M., Kolb, C. E., Baltensperger, U., and Worsnop, D. R.: Evolution of organic aerosols in the atmosphere, Science, 326, 1525-1529, doi:10.1126/science.1180353, 2009.

Kamens, R. and Jaoui, M.: Modeling aerosol formation from $\alpha$ pinene $+\mathrm{NO}_{\mathrm{x}}$ in the presence of natural sunlight using gas-phase kinetics and gas-particle partitioning theory, Environ. Sci. Technol., 35, 1394-1405, 2001.

Krewski, D., Jerrett, M., Burnett, R. T., Ma, R., Hughes, E., Shi, Y., Turner, M. C., Pope III, C. A., Thurston, G., Calle, E. E., and Thun, M. J.: Extended follow-up and spatial analysis of the American Cancer Society Study linking particulate air pollution and mortality, Tech. rep., Health Effects Institute, Boston, Massachusetts, 2009.

Kroll, J. H., Ng, N. L., Murphy, S. M., Flagan, R. C., and Seinfeld, J. H.: Secondary organic aerosol formation from isoprene photooxidation, Environ. Sci. Technol., 40, 1869-1877, 2006.

Lambe, A. T., Ahern, A. T., Williams, L. R., Slowik, J. G., Wong, J. P. S., Abbatt, J. P. D., Brune, W. H., Ng, N. L., Wright, J. P., Croasdale, D. R., Worsnop, D. R., Davidovits, P., and Onasch, T. B.: Characterization of aerosol photooxidation flow reactors: heterogeneous oxidation, secondary organic aerosol formation and cloud condensation nuclei activity measurements, Atmos. Meas. Tech., 4, 445-461, doi:10.5194/amt-4-445-2011, 2011.

Lane, T. E., Donahue, N. M., and Pandis, S. N.: Effect of $\mathrm{NO}_{\mathrm{X}}$ on secondary organic aerosol concentrations, Environ. Sci. Technol., 41, 3984-3990, 2008.

Mang, S. A., Henricksen, D. K., Bateman, A. P., Andersen, M. P. S., Blake, D. R., and Nizkorodov, S. A.: Contribution of carbonyl photochemistry to aging of atmospheric secondary organic aerosol, J. Phys. Chem. A, 112, 8337-8344, 2008.

Martinez, M., Harder, H., Kovacs, T. A., Simpas, J. B., Bassis, J., Lesher, R., Brune, W. H., Frost, G. J., Williams, E. J., Stroud, C. A., Jobson, B. T., Roberts, J. M., Hall, S. R., Shetter, R. E., Wert, B., Fried, A., Alicke, B., Stutz, J., Young, V. L., White, A. B., and Zamora, R. J.: $\mathrm{OH}$ and $\mathrm{HO}_{2}$ concentrations, sources, and loss rates during the Southern Oxidants Study in Nashville, Tennessee, summer 1999, J. Geophys. Res., 108, 4617, doi:10.1029/2003JD003551, 2003.

Martinez, M., Harder, H., Kubistin, D., Rudolf, M., Bozem, H., Eerdekens, G., Fischer, H., Klüpfel, T., Gurk, C., Königstedt, R., Parchatka, U., Schiller, C. L., Stickler, A., Williams, J., and Lelieveld, J.: Hydroxyl radicals in the tropical troposphere over the Suriname rainforest: airborne measurements, Atmos. Chem. Phys., 10, 3759-3773, doi:10.5194/acp-10-3759-2010, 2010.

Meyer, N. K., Duplissy, J., Gysel, M., Metzger, A., Dommen, J., Weingartner, E., Alfarra, M. R., Prevot, A. S. H., Fletcher, C., Good, N., McFiggans, G., Jonsson, A. M., Hallquist, M., Baltensperger, U., and Ristovski, Z. D.: Analysis of the hygroscopic and volatile properties of ammonium seeded and unseeded SOA particles, Atmos. Chem. Phys., 9, 721-732, doi:10.5194/acp-9721-2009, 2009. 
Ng, N. L., Kroll, J. H., Keywood, M. D., Bahreini, R., Varutbangkul, V., Flagan, R. C., Seinfeld, J. H., Lee, A., and Goldstein, A. H.: Contribution of first- versus second-generation products to secondary organic aerosols formed in the oxidation of biogenic hydrocarbons, Environ. Sci. Technol., 40, 2283-2297, 2006.

Ng, N. L., Chhabra, P. S., Chan, A. W. H., Surratt, J. D., Kroll, J. H., Kwan, A. J., McCabe, D. C., Wennberg, P. O., Sorooshian, A., Murphy, S. M., Dalleska, N. F., Flagan, R. C., and Seinfeld, J. H.: Effect of $\mathrm{NO}_{\mathrm{x}}$ level on secondary organic aerosol (SOA) formation from the photooxidation of terpenes, Atmos. Chem. Phys., 7, 5159-5174, doi:10.5194/acp-7-5159-2007, 2007a.

Ng, N. L., Kroll, J. H., Chan, A. W. H., Chhabra, P. S., Flagan, R. C., and Seinfeld, J. H.: Secondary organic aerosol formation from m-xylene, toluene, and benzene, Atmos. Chem. Phys., 7, 3909-3922, doi:10.5194/acp-7-3909-2007, 2007b.

Nozière, B., Barnes, I., and Becker, K. H.: Product study and mechanisms of the reactions of $\alpha$-pinene and of pinonaldehyde with OH radicals, J. Geophys. Res.-Atmos., 104, 23645-23656, 1999.

Odum, J. R., Hoffmann, T., Bowman, F., Collins, D., Flagan, R. C., and Seinfeld, J. H.: Gas/particle partitioning and secondary organic aerosol yields, Environ. Sci. Technol., 30, 2580-2585, 1996.

Olander, D.: General Thermodynamics, CRC Press, 2007.

Pankow, J. F.: An absorption model of gas/particle partitioning of organic compounds in the atmosphere, Atmos. Environ., 28, 185-188, doi:10.1016/1352-2310(94)90093-0, 1994.

Pathak, R. K., Stanier, C. O., Donahue, N. M., and Pandis, S. N.: Ozonolysis of $\alpha$-pinene at atmospherically relevant concentrations: Temperature dependence of aerosol mass fractions (yields), J. Geophys. Res.-Atmos., 112, D03201, doi:10.1029/2006JD007436, 2007.

Peeters, J., Vereecken, L., and Fantechi, G.: The detailed mechanism of the $\mathrm{OH}$-initiated atmospheric oxidation of $\alpha$-pinene: a theoretical study, Phys. Chem. Chem. Phys., 3, 5489-5504, 2001.

Poling, B. E., Prausnitz, J. M., and O'Connell, J. P.: The properties of gases and liquids, McGraw-Hill, 2001.

Pope III, C. A., Burnett, R. T., Thun, M. J., Calle, E. E., Krewski, D., Ito, K., and Thurston, G. D.: Lung cancer, cardiopulmonary mortality, and long-term exposure to fine particulate air pollution, $\mathrm{J}$. Am. Med. Assoc., 287, 1132-1141, 2002.

Presto, A., Huff Hartz, K., and Donahue, N.: Secondary organic aerosol production from terpene ozonolysis. 2. Effect of $\mathrm{NO}_{\mathrm{x}}$ concentration, Environ. Sci. Technol., 39, 7046-7054, doi:10.5194/acp-10-4377-2010, 2005a.

Presto, A. A., Huff Hartz, K. E., and Donahue, N. M.: Secondary organic aerosol production from terpene ozonolysis. 1. Effect of UV radiation, Environ. Sci. Technol., 39, 7036-7045, 2005 b.

Pye, H. O. T. and Seinfeld, J. H.: A global perspective on aerosol from low-volatility organic compounds, Atmos. Chem. Phys., 10, 4377-4401, doi:10.5194/acp-10-4377-2010, 2010.

Pye, H. O. T., Chan, A. W. H., Barkley, M. P., and Seinfeld, J. H.: Global modeling of organic aerosol: the importance of reactive nitrogen $\left(\mathrm{NO}_{\mathrm{x}}\right.$ and $\left.\mathrm{NO}_{3}\right)$, Atmos. Chem. Phys., 10, 1126111276, doi:10.5194/acp-10-11261-2010, 2010.

Raatikainen, T. and Laaksonen, A.: Application of several activity coefficient models to water-organic-electrolyte aerosols of atmospheric interest, Atmos. Chem. Phys., 5, 2475-2495, doi:10.5194/acp-5-2475-2005, 2005.
Saathoff, H., Naumann, K.-H., Möhler, O., Jonsson, Å. M., Hallquist, M., Kiendler-Scharr, A., Mentel, T. F., Tillmann, R., and Schurath, U.: Temperature dependence of yields of secondary organic aerosols from the ozonolysis of $\alpha$-pinene and limonene, Atmos. Chem. Phys., 9, 1551-1577, doi:10.5194/acp-9-15512009, 2009.

Shilling, J. E., Chen, Q., King, S. M., Rosenoern, T., Kroll, J. H., Worsnop, D. R., McKinney, K. A., and Martin, S. T.: Particle mass yield in secondary organic aerosol formed by the dark ozonolysis of $\alpha$-pinene, Atmos. Chem. Phys., 8, 2073-2088, doi:10.5194/acp-8-2073-2008, 2008.

Smith, J. D., Kroll, J. H., Cappa, C. D., Che, D. L., Liu, C. L., Ahmed, M., Leone, S. R., Worsnop, D. R., and Wilson, K. R.: The heterogeneous reaction of hydroxyl radicals with submicron squalane particles: a model system for understanding the oxidative aging of ambient aerosols, Atmos. Chem. Phys., 9, 3209-3222, doi:10.5194/acp-9-3209-2009, 2009.

Solomon, S., Qin, D., Manning, M., Chen, Z., Marquis, M., Averyt, K. B., Tignor, M., and Miller, H. L. (Eds.): Climate change 2007: the physical science basis, Cambridge University Press, 2007.

Stanier, C. O., Donahue, N., and Pandis, S. N.: Parameterization of secondary organic aerosol mass fractions from smog chamber data, Atmos. Environ., 42, 2276-2299, 2008.

Stavrakou, T., Müller, J.-F., De Smedt, I., Van Roozendael, M., van der Werf, G. R., Giglio, L., and Guenther, A.: Evaluating the performance of pyrogenic and biogenic emission inventories against one decade of space-based formaldehyde columns, Atmos. Chem. Phys., 9, 1037-1060, doi:10.5194/acp-9-1037-2009, 2009.

Stavrakou, T., Müller, J.-F., Peeters, J., Razavi, A., Clarisse, L., Clerbaux, C., Coheur, P.-F., Hurtmans, D., De Mazière, M., Vigouroux, C., Deutscher, N. M., Griffith, D. W. T., Jones, N., and Paton-Walsh, C.: Satellite evidence for a large source of formic acid from boreal and tropical forests, Nat. Geosci., 5, 2630, doi:10.1038/ngeo1354, 2012.

Takekawa, H., Minoura, H., and Yamazaki, S.: Temperature dependence of secondary organic aerosol formation by photooxidation of hydrocarbons, Atmos. Environ., 37, 3413-3424, doi:10.1016/S1352-2310(03)00359-5, 2003.

Tsigaridis, K. and Kanakidou, M.: Secondary organic aerosol importance in the future atmosphere, Atmos. Environ., 41, 46824692, 2007.

Tsigaridis, K., Krol, M., Dentener, F. J., Balkanski, Y., Lathière, J., Metzger, S., Hauglustaine, D. A., and Kanakidou, M.: Change in global aerosol composition since preindustrial times, Atmos. Chem. Phys., 6, 5143-5162, doi:10.5194/acp-6-5143-2006, 2006.

Utembe, S. R., Watson, L. A., Shallcross, D. E., and Jenkin, M. E.: A Common Represetative Intermediates (CRI) mechanism for VOC degradation. Part 3: development of a secondary organic aerosol module, Atmos. Environ., 43, 1982-1990, 2009.

Valorso, R., Aumont, B., Camredon, M., Raventos-Duran, T., Mouchel-Vallon, C., Ng, N. L., Seinfeld, J. H., Lee-Taylor, J., and Madronich, S.: Explicit modelling of SOA formation from $\alpha$-pinene photooxidation: sensitivity to vapour pressure estimation, Atmos. Chem. Phys., 11, 6895-6910, doi:10.5194/acp-116895-2011, 2011.

Vereecken, L. and Peeters, J.: Decomposition of substituted alkoxy radicals - part 1: a generalized structure-activity relationship for 
reaction barrier heights, Phys. Chem. Chem. Phys., 11, 90629074, 2009.

Vereecken, L. and Peeters, J.: A structure-activity relationship for the rate coefficient of H-migration in substituted alkoxy radicals, Phys. Chem. Chem. Phys., 12, 12608-12620, 2010.

Vereecken, L., Müller, J.-F., and Peeters, J.: Low-volatility polyoxygenates in the $\mathrm{OH}$-initiated atmospheric oxidation of $\alpha$ pinene: impact of non-traditional peroxyl radical chemistry, Phys. Chem. Chem. Phys., 9, 5241-5248, 2007.

Volkamer, R., Ziemann, P. J., and Molina, M. J.: Secondary Organic Aerosol Formation from acethylene $\left(\mathrm{C}_{2} \mathrm{H}_{2}\right)$ : seed effect on SOA yields due to organic photochemistry in the aerosol aqueous phase, Atmos. Chem. Phys., 9, 1907-1928, doi:10.5194/acp9-1907-2009, 2009.

Xia, A. G., Michelangeli, D. V., and Makar, P. A.: Box model studies of the secondary organic aerosol formation under different $\mathrm{HC} / \mathrm{NO}_{\mathrm{x}}$ conditions using the subset of the Master Chemical Mechanism for $\alpha$-pinene oxidation, J. Geophys. Res., 113, D10301, doi:10.1029/2007JD008726, 2008.
Xia, A. G., Michelangeli, D. V., and Makar, P. A.: Mechanism reduction for the formation of secondary organic aerosol for integration into a 3-dimensional regional air quality model: $\alpha$ pinene oxidation system, Atmos. Chem. Phys., 9, 4341-4362, doi:10.5194/acp-9-4341-2009, 2009.

Xia, A. G., Stroud, C. A., and Makar, P. A.: Development of a simple unified volatility-based scheme (SUVS) for secondary organic aerosol formation using genetic algorithms, Atmos. Chem. Phys., 11, 6185-6205, doi:10.5194/acp-11-6185-2011, 2011.

Xia, G.: Modeling secondary organic aerosol formation using a simple scheme in a 3-dimensional air quality model and performing systematic mechanism reduction for a detailed chemical mechanism, Ph.D. thesis, York University, Toronto, Ontario, 2006. 